\title{
Performance of a Building Integrated Photovoltaic/Thermal Concentrator for Facade
}

\section{Applications}

\section{Piratheepan and T.N. Anderson ${ }^{1}$}

School of Engineering, Computer and Mathematical Sciences, Auckland University of Technology, Auckland 1142, New Zealand

\begin{abstract}
The use of building integrated photovoltaic/thermal (BIPVT) concentrators is an effective way to harness solar energy within the built environment, particularly for façade applications. However, in order to precisely predict the overall performance of building integrated façade collectors it is crucial to have a validated model that represents such systems.

In this study, a combined optical and thermal model was developed to describe the performance of a façade integrated BIPVT solar concentrator system and subsequently was validated with a physical prototype. Using the validated model, it was shown that key parameters such as tube spacing, and thermal conductivity between the solar cell and the absorber have a significant effect on the overall efficiency.

Finally, it is suggested that façade integrated BIPVT solar concentrator systems would serve as a complement to roof mounted photovoltaic systems, and that this may be a step towards net zero energy buildings.
\end{abstract}

Keywords: building integrated photovoltaic/thermal, façade, concentrator, BIPVT

\section{Introduction}

Energy consumption in the built environment accounts for nearly one third of global energy demand (IEA 2011). A significant portion of this could be met through onsite energy generation utilising solar energy. However, traditional solar energy systems such as photovoltaic panels or solar thermal collectors retrofitted onto buildings after they have been built may result in poor aesthetics and suboptimal energy outputs. Therefore, integration of combined photovoltaic/solar thermal collectors into a building's fabric could provide greater opportunity for the use of renewable energy technologies in buildings.

\footnotetext{
${ }^{1}$ Corresponding Author: Tel.: +64 99219999 Ext 8075
}

E-mail address: timothy.anderson@aut.ac.nz 
Generating thermal and electrical energy simultaneously from solar irradiation using photovoltaic/thermal (PVT) systems is an area of research that has received significant attention in recent years (Anderson et al. 2009, Ibrahim et al. 2014, Fudholi et al. 2014, Tripanagnostopoulos 2012). However, there have been relatively few attempts to utilize such systems with low concentration ratio concentrating systems to increase the radiation incident on the PVT absorber, and even fewer that incorporate such systems into the fabric of a building.

A significant advantage of low concentration reflectors is that they do not need to track the sun, making them ideal for integration into a building's facade, though by doing this they will have a lower acceptance angle range than tracking collectors (Rabl, 1976). Despite this disadvantage, low concentration ratio collectors offer the advantage of collecting diffuse radiation as well as the beam component (Petter et al. 2012) and the possibility of using the traditional silicon solar cells less.

In their study, Tripanagnostopoulos et al (2002), analysed PVT combined collectors incorporating low concentration ratio booster reflectors with a view to achieving high combined efficiency. In a parallel study, Tselepis and Tripanagnostopoulos (2002) performed a life cycle assessment of the combined collector and concluded that they were more cost competitive, had a shorter payback time and less environmental impact than that of standalone PV panels. As such, the combination of low concentration ratio reflective elements along with hybrid absorbers may further improve the cost competitiveness of the system by increasing the radiation on the absorber plate. Similarly, a study by Gajbert, et al. (2007) found that low concentration ratio PVT modules have advantages over traditional modules and proposed a PVT collector with a parabolic reflector.

However, there appears to be few active attempts to utilise concentrating building integrated PVT systems, and a lack of detail in describing their combined thermal/electrical performances. Moreover, there are few studies that have investigated systems with a static reflector combined with a hybrid absorber for façade applications. In light of this, this work examines the design and performance of a PVT system that incorporates a reflective element with a view to increasing the radiation on a photovoltaic/thermal absorber plate, suitable for integration into a building façade.

\section{Optical assessment of a BIPVT concentrator}

Based on the literature, a complete design of BIPVT concentrating collector has several challenges at the design phase; in particular, a suitable optical arrangement needs to be found. In considering a solar concentrator, the most common defining characteristic is the concentration ratio, defined by the ratio of the aperture area to the receiver area. Obviously it is desirable to maximize this parameter in order to improve the performance of the collector. However, for façade integrated collectors it is far more practical to use static solar concentrators with medium to low concentration ratios. With this configuration it is not necessary to track the sun thus making them ideal for use as building integrated solar collectors, where they are the part of the building and hardly movable. 
One of the key benefits of low concentration ratio collectors is that they may work with an absorber equipped with conventional silicon solar cells to produce significant amounts of electrical energy. These absorbers are comparatively cheap, readily available in the market and do not need the precise optical design of high/medium concentrator devices. Research on low concentration reflectors conducted in the mid-70's (McDaniels et al. 1975, Rab1 1976) was mainly around two distinctly different reflectors; one a modified compound parabolic reflector and the other based on a simple flat plate reflector, often referred to as a booster reflector.

Parabolic reflectors are one of the most widely used non-imaging concentrators; used in linear and trough collectors. By modifying the dimensions of the reflectors (either by truncating or extending) higher concentration ratios can be achieved. Similarly, changing the area of the reflector material allows variation of the acceptance angle without changing the concentration ratio for a particular range of angles. In this regard, systems using truncated semi parabolic concentrators have been proposed for building facade integrated collectors in the past (Gajbert et al. 2007, Brogren 2004).

That said, flat reflectors are one of the simplest ways to increase the insolation incident on a solar collector. Figure 1 shows a typical flat reflector collector design with an absorber inclination angle $\theta$, where $L_{R}$ and $L_{C}$ are the lengths of the booster reflector and the collector respectively.

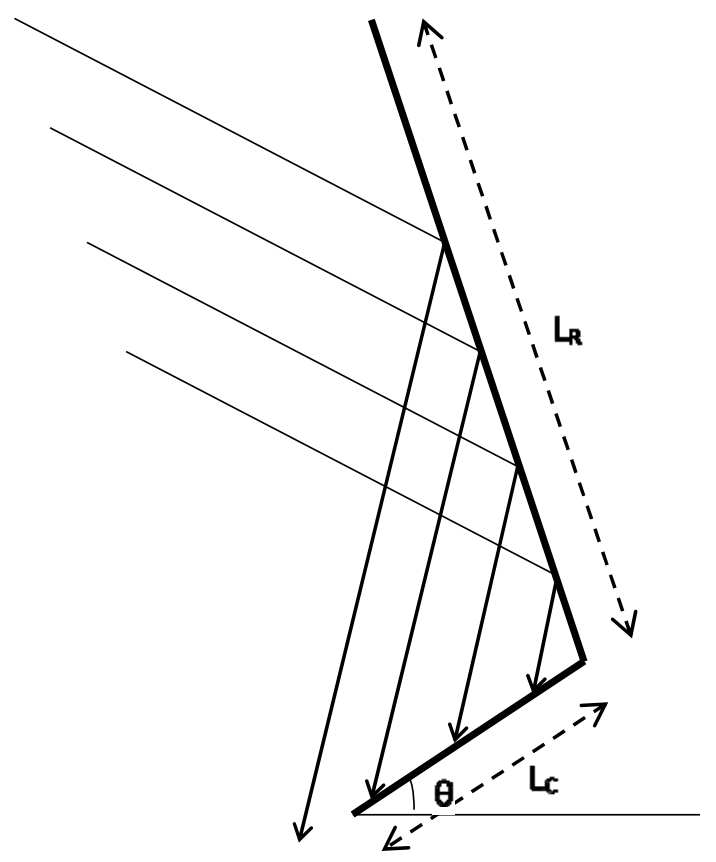

Figure 1 Flat reflector collector

By changing the size of the reflector, the geometric concentration ratio $\left(\mathrm{L}_{\mathrm{R}} / \mathrm{L}_{\mathrm{C}}\right)$ can be manipulated to achieve a higher level of solar radiation on the absorber. Unlike a flat plate collector, inclination angles of both the absorber and reflector can be manipulated to achieve an optimum output (Tanaka 2011). 
Although concentrating systems with flat reflective elements have been used in different applications, the possibility of using them in façade applications appears to have been ignored.

Based on the suitability of CPC and flat reflectors for static concentrators, it was decided to examine the concentration ratio of these two possible configurations for a façade integrated concentrator. As such, a collector with a parabolic reflector incorporated similar to that described in Gajbert et al. (2007) and a second with a flat reflector, as shown in Figure 2, were examined.

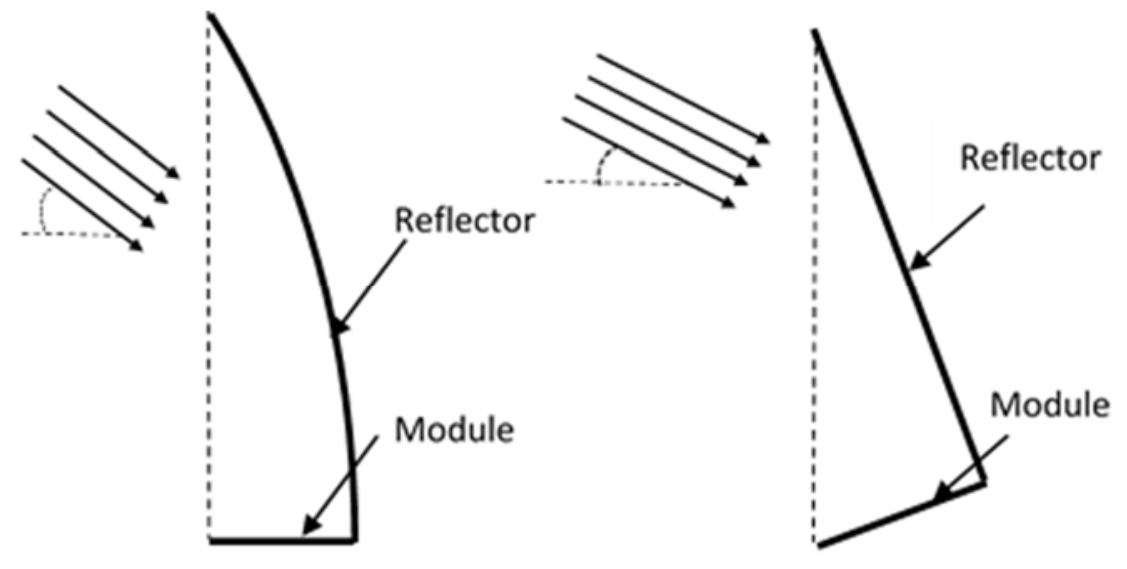

Figure 2 Façade integrated concentrator profiles

\subsection{Comparison of possible geometries}

To characterize the performance of the two systems it was decided to use the ray-tracing program FRED. FRED is an optical engineering software program that is capable of performing non-sequential ray tracing analysis of non-imaging optics, such as solar concentrators (FRED 2016). To simplify the ray tracing, it was decided to perform a one dimensional ray tracing study with a collimated optical source of rays, as an approximation of the beam component of solar radiation. It was assumed that the reflectors were perfect reflectors while the absorbers (the surface to be analysed) were perfect absorbers. To make a fair comparison of the two concentrators the length of each reflector was approximately equal, as was the width of the absorber module, such that the geometric concentration ratio for both was approximately 3.6. In addition, a horizontal absorber of the same dimensions as that used with the concentrators was modelled to serve as a benchmark.

With each system the illumination pattern on the absorber plate was observed while varying the solar elevation angle ( $\alpha$ - measured up from horizon) of the rays between 0 and $90^{\circ}$. Figure 3 shows the total number of rays received by the absorbers from both modules compared to the reference module for different elevation angles of the source. If the number of ray's incident on the absorbers are then normalised against the number of ray's incident on the horizontal reference we can determine a relative concentration ratio, as shown in Figure 3. 


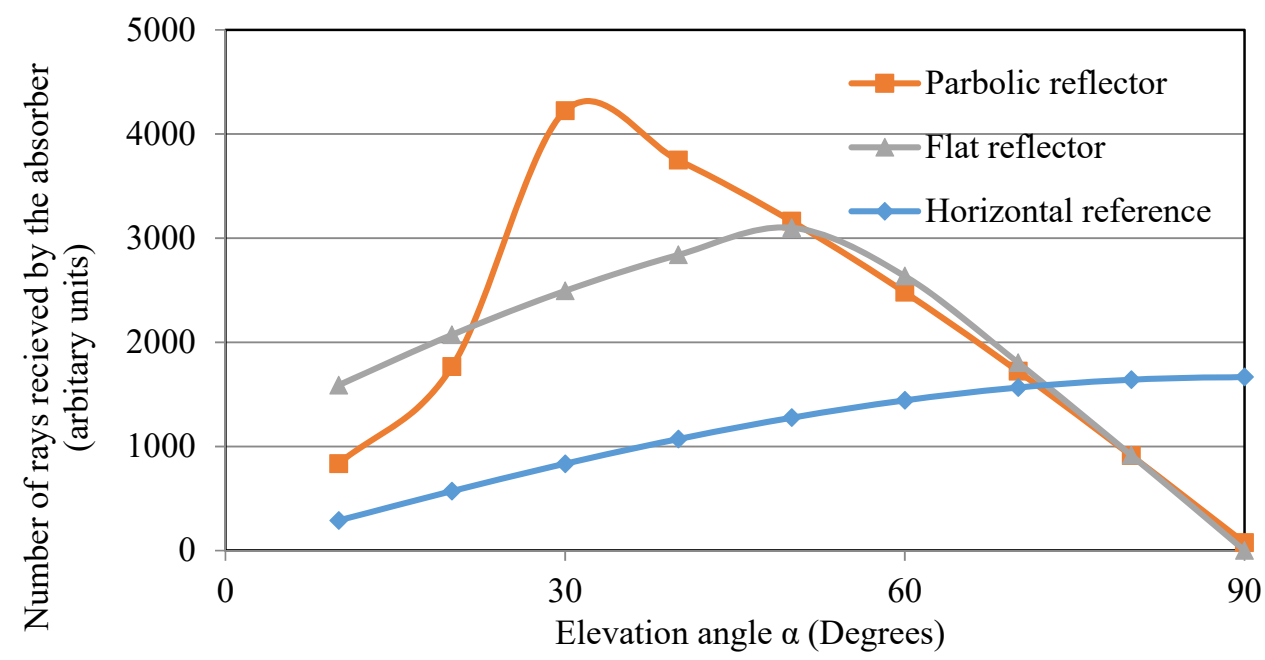

Figure 3 Number of rays hitting the absorber vs elevation angle $(\alpha)$ of the source

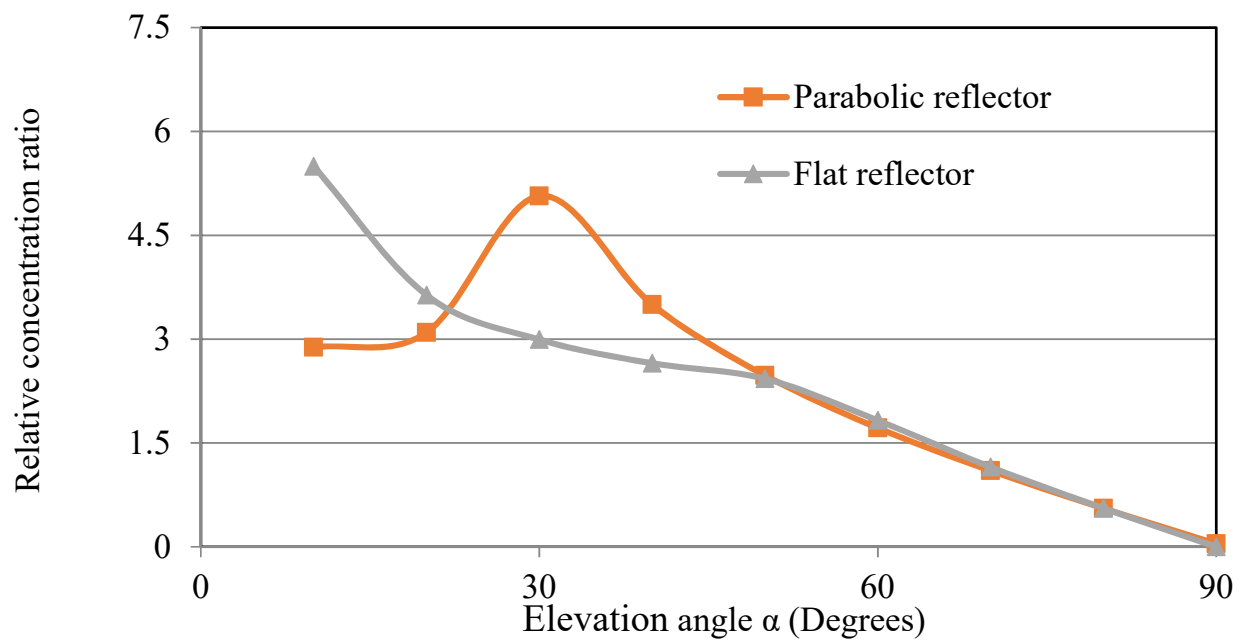

Figure 4 Relative concentration ratio vs elevation angle $(\alpha)$ of the source

By considering both Figure 3 and Figure 4, the conclusion could be drawn that the parabolic reflectors give better performance at a range of elevation angles compared to the flat reflector, as Brogren and Karlsson (2002) suggested. However, in drawing this conclusion it is important to also consider the local concentration ratio (illumination pattern) on the absorber.

Figure 5 shows the variation in illumination across the width of the absorber with the parabolic reflector (taking the junction of absorber and reflector as the origin). From this, for the mid-range elevation angles, there is a significant non-uniformity in the intensity on the absorber. For example, at an elevation angle of $60^{\circ}$ the illumination near the apex is over seven times that at the edge of the absorber. This shows that the illumination profile of parabolic reflectors tends to be non-uniform and the patterns are discrete and discontinuous in nature due to them focusing the to a line. 


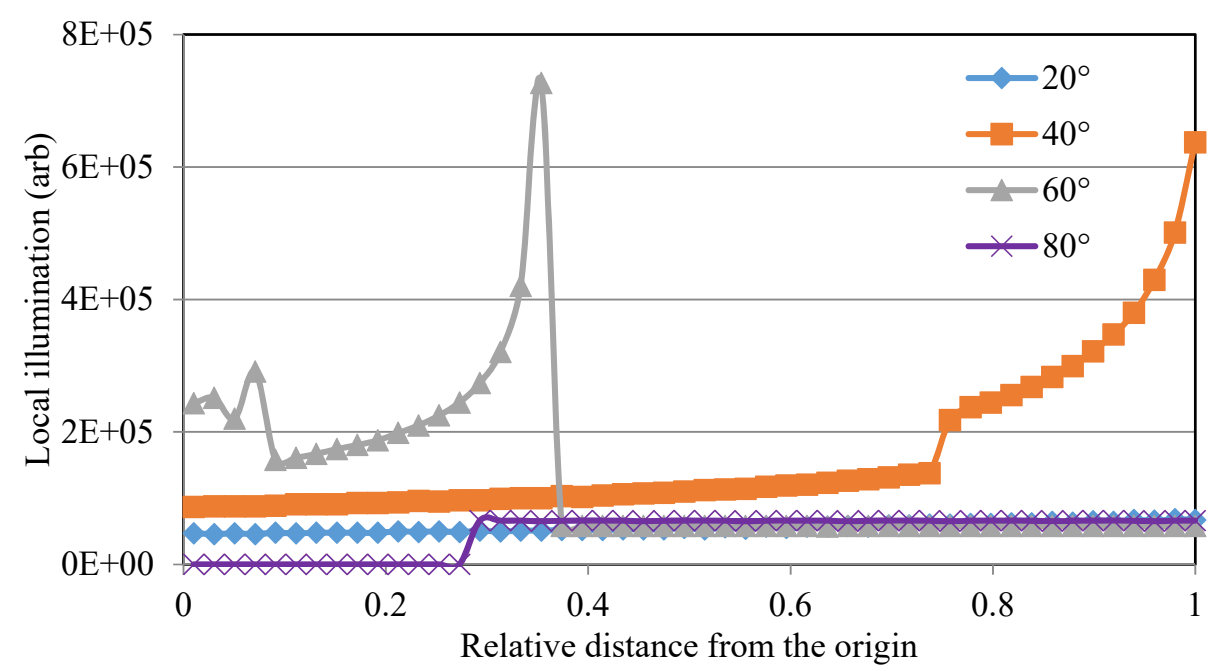

Figure 5 Illumination on the absorber module at various elevation angles under parabolic reflector

Now if we consider the illumination profile from a flat plate reflector, as shown in Figure 6, we can see that the magnitude of the illumination is in on average lower than that of a parabolic reflector. This is interesting, because it has the same dimensions as the parabolic reflector, but the illumination is more uniform in its distribution. That is to say, the local concentration ratio across the absorber with a flat reflector is far more consistent at any particular elevation angle. Hence, for a photovoltaic/thermal absorber, each part of the module will produce similar electric current output, so that the undesirable effect of hotspots and thermal energy dissipation otherwise caused under the parabolic reflectors can be avoided. In this respect flat reflectors could be considered analogous to a circular mirror with an infinite radius that will focus on a plane.

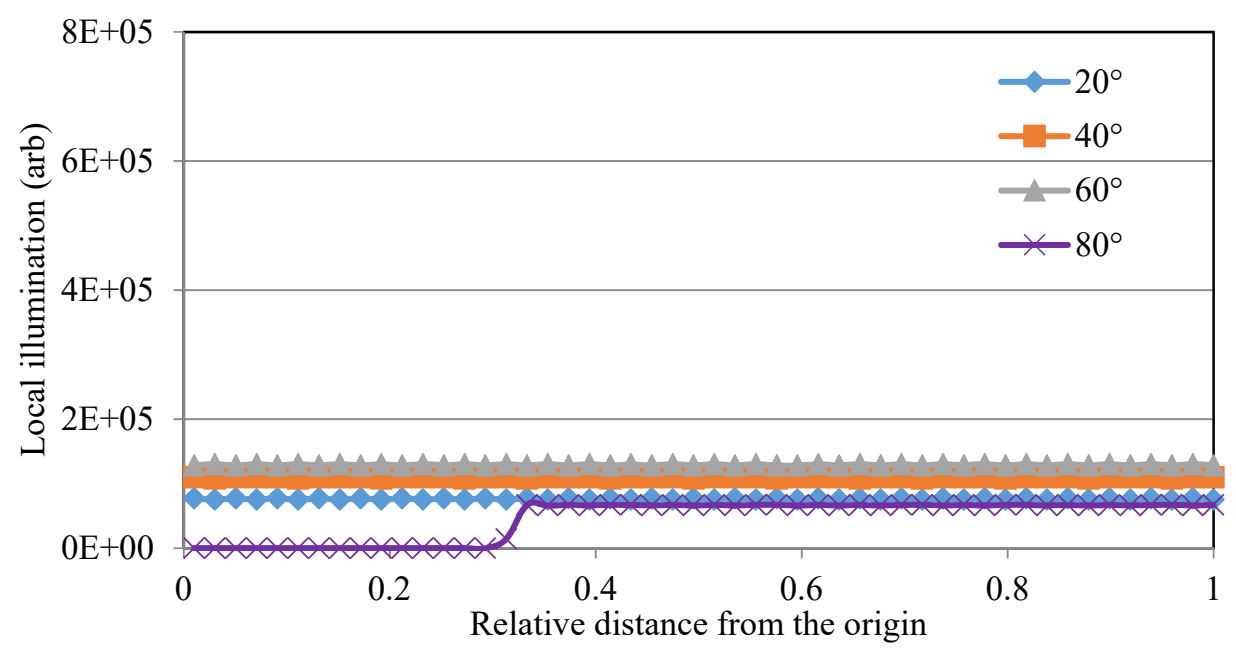

Figure 6 Illumination on the absorber module at various elevation angles under flat reflector It can be seen that the flat reflector gives a uniform local concentration ratio across the absorber for all conditions. Hence, the electric current produced at any point on a cell under a flat plate reflector will be similar. This reduces the cross currents that cause the hotspot across the cell and so would appear to be an appropriate compromise for BIPVT concentrator systems. 
From these results, it is possible to draw the conclusion that parabolic reflectors are well suited for application in mid-latitude locations. However, they are perhaps better suited to thermal applications where non-uniform illumination of an absorber surface is less problematic. If one were to utilize a parabolic reflector for a BIPVT concentrator, the non-uniform illumination would cause high ohmic losses and would also produce internal current flow, even when it is open circuited. Hence, it may not improve the performance of the module due to the cross currents forming hotspots in lower irradiated cells, rather, this may lead to permanent defects or premature failure of cells (Yang et al. 1991). As such, it reinforces the benefits of flat reflectors for BIPVT systems and so flat reflectors form the basis of this work.

\subsection{Modelling the optical characteristics of a flat reflector}

Now, in order to verify a suitable geometry for a building integrated concentrator with a flat reflector it is important to understand the effect of the absorber and reflector tilt angle on the optical performance of the collector. As such the FRED ray tracing software package was used to analyse the effect of the parameters such as reflector tilt $\left(\theta_{\mathrm{r}}\right)$, absorber tilt $\left(\theta_{\mathrm{a}}\right)$ and solar elevation angle $(\alpha)$ on the optical performance of a collector, as shown in Figure 7.

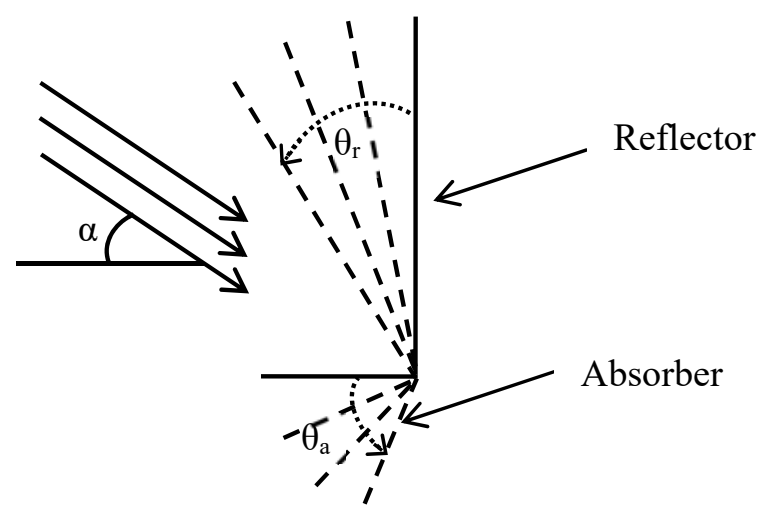

Figure 7 Angle of rotation of reflector and the absorber combination

As described previously, to perform the ray tracing, it was decided to use a collimated source as an approximation of beam component of solar radiation. To explore the angular relationship between the absorber and the reflector, it was decided to vary the tilt angle of the absorber and the reflector over a range of conditions and combinations. Subsequently, the number of rays received by the absorber was determined for a range of source elevation angles.

As shown in Figures 8,9,10 and 11 increasing the inclination angle of the reflectors decreases the ability of the absorber to receive more radiation at higher elevation angles. Furthermore, as shown in Figure 10 , at an absorber angle of $20^{\circ}$ to the horizontal, the total number of rays received by the absorber over a range of elevation angles is high without it becoming shaded by the reflector at higher elevation angles.

The reason for this being that if the reflector tilt is increased, the reflector starts to shade the absorber at higher solar elevation angles, while when the absorber angle is increased the proportion of the rays 
missing the absorber increases at lower elevation angles. To keep the aperture of the collector significantly high, and gather a significant portion of the radiation at moderate elevation angles without losing much radiation at high and low elevation angles, a reflector-absorber combination with approximately $20^{\circ}$ tilt angle would seem appropriate.

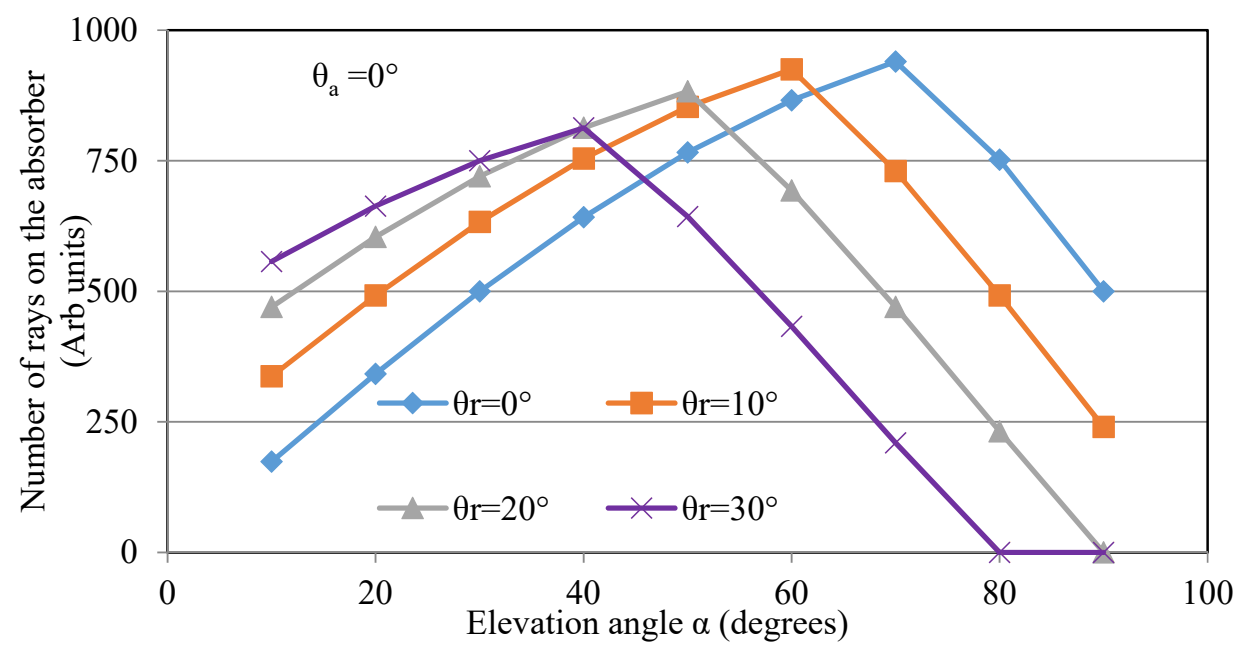

Figure 8 Number of rays received by the absorber at different elevation and reflector angles when the absorber is fixed at $0^{\circ}$

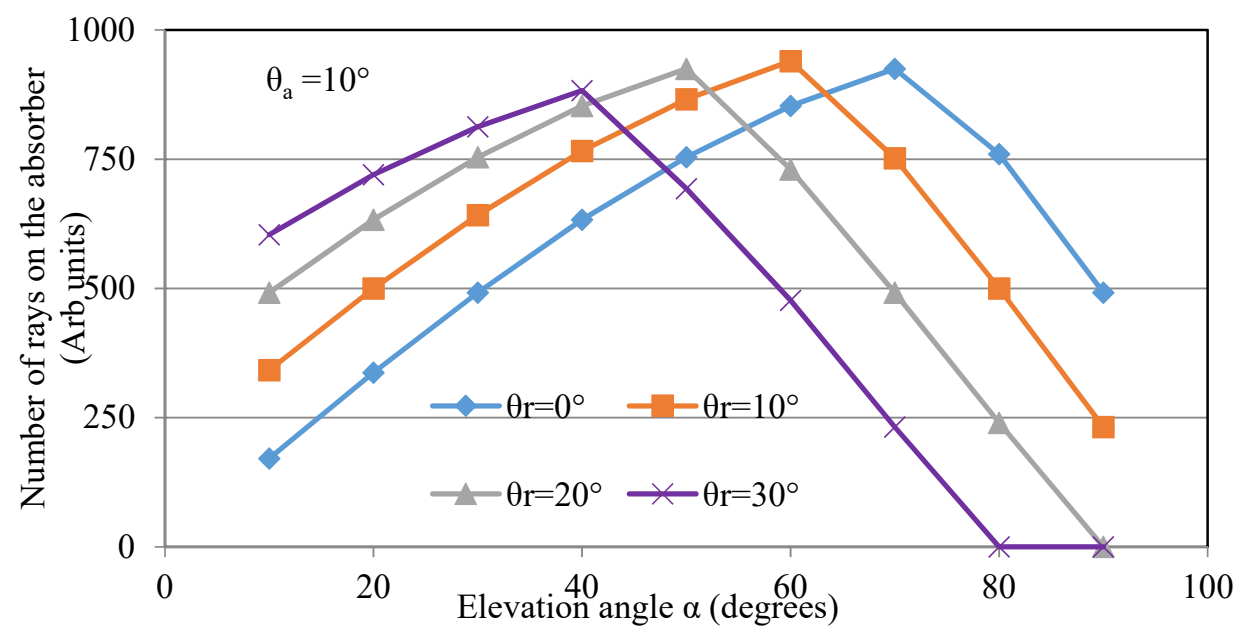

Figure 9 Number of rays received by the absorber at different elevation and reflector angles when the absorber is fixed at $10^{\circ}$ 


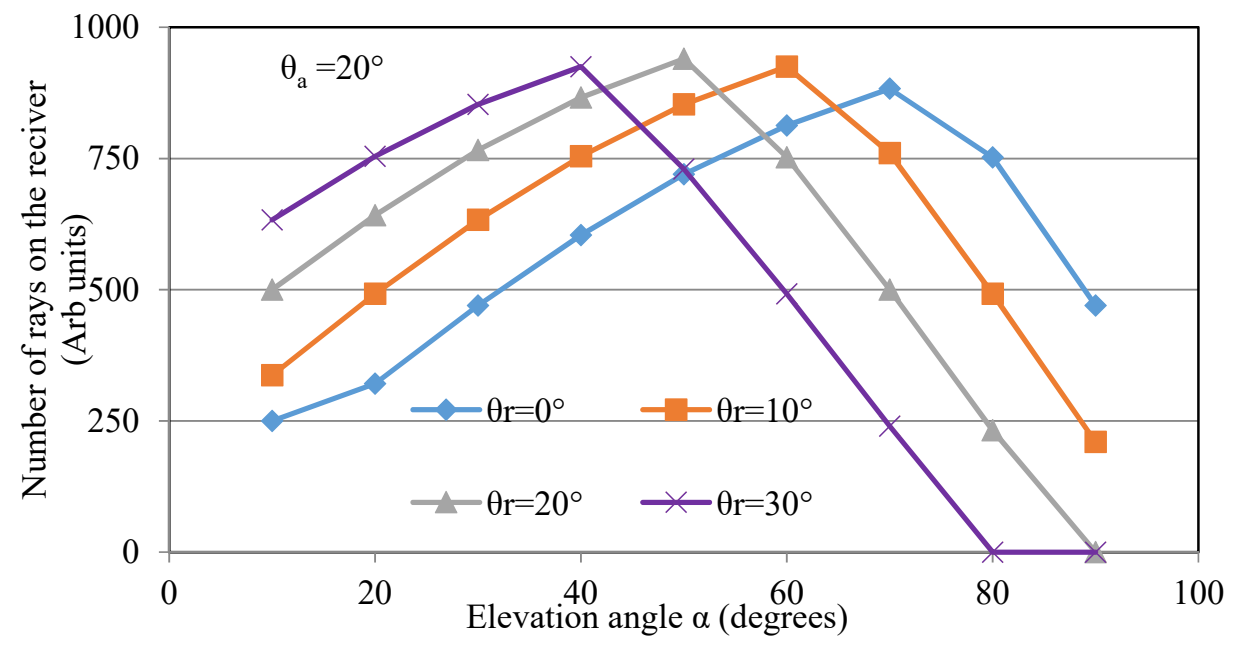

Figure 10 Number of rays received by the absorber at different elevation and reflector angles when the absorber is fixed at $20^{\circ}$

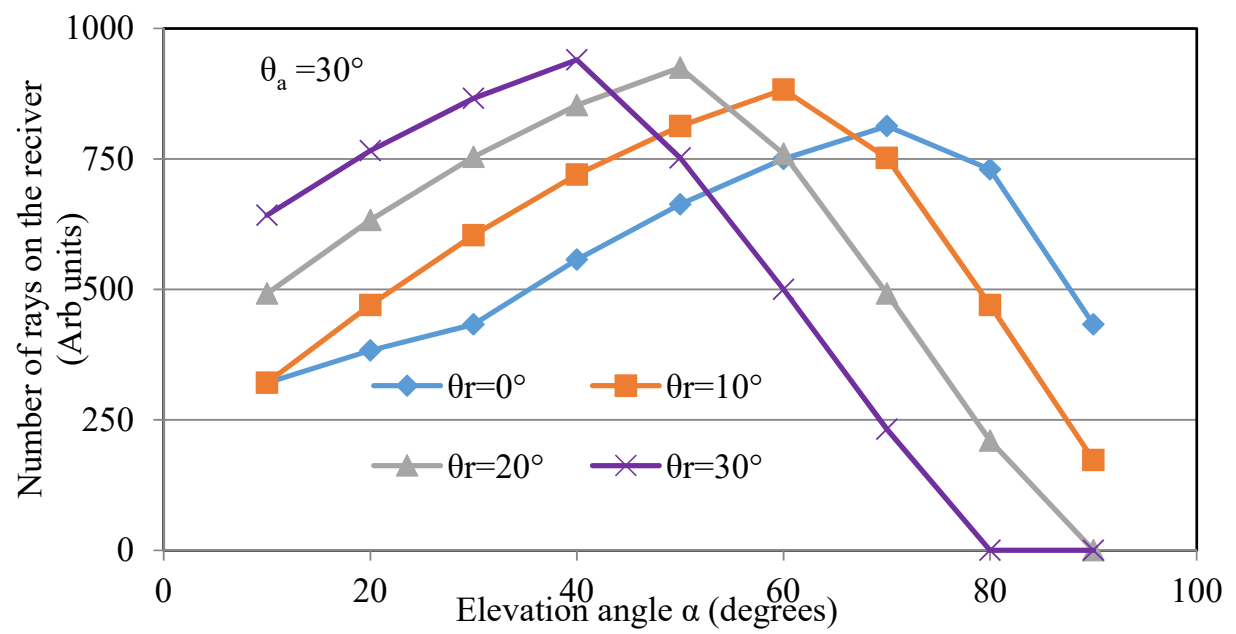

Figure 11 Number of rays received by the absorber at different elevation and reflector angles when the absorber is fixed at $30^{\circ}$

Now, although ray tracing was able to provide insight into potential geometric configurations of the concentrator, these results are not particularly generalizable. Hence, to investigate the concentration ratio of the particular combination, it was decided to develop a geometric relationship in terms of the principle angles.

Although the geometric concentration ratio is defined by the ratio of area of the aperture and the absorber, the relative concentration ratio defined by Kostic, et al. (2010) is a more practical expression of concentration ratio $C$, as shown in equation 1 ,

$$
C=\frac{G_{t o t}}{G_{n e t}}
$$

Here the $G_{t o t}$ is the total radiation received by the absorber plate with the reflector while the $G_{n e t}$ is the total radiation received by a horizontal absorber without any reflector. Given that the beam radiation on 
a horizontal surface can be easily determined, the total radiation on to the absorber plate can be estimated if the appropriate geometrical relationship is established in terms of direct $\left(G_{d i r}\right)$ and reflected $\left(G_{r e f}\right)$ radiation.

As a significant portion of the radiation falling on the absorber comes from the reflector, it is essential to include the reflectance of the reflector to precisely calculate the radiation on the absorber. By incorporating the reflectance $\rho_{A l}$ of the reflector, $C$ can be expressed as in equation 2 .

$$
C=\frac{G_{d i r}+\rho_{A l} G_{r e f}}{G_{t o t}}
$$

Exploring this further, considering Figure 12; if $\alpha$ is the solar elevation angle and $\beta$ is the inclination angle of the absorber plate from the horizontal axis. When the elevation angle $\alpha<(90-2 \beta)$, some of the reflected rays will not be incident on the absorber surface, as shown in Figure 13(i).

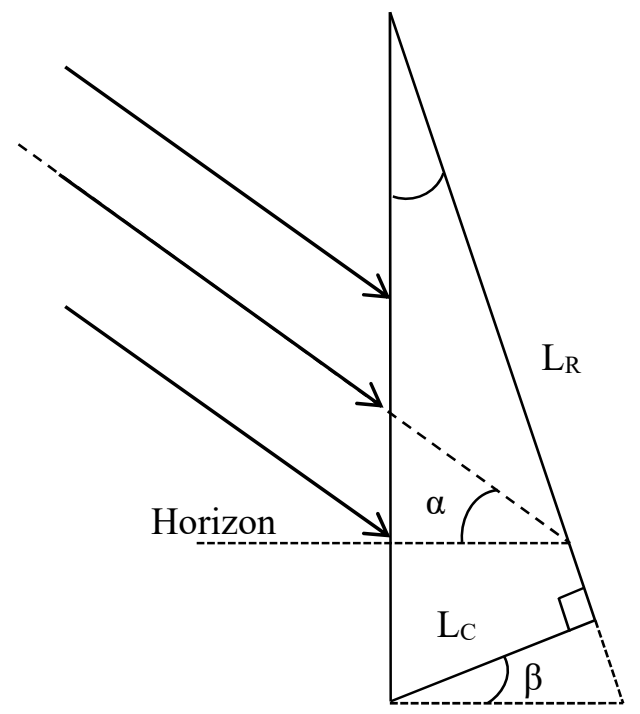

Figure 12 Schematic representation of a collector with a flat reflector

Furthermore, when the elevation angle $\alpha$ is between $(90-2 \beta)<\alpha<(90-\beta)$, the reflector will receive the sum of all the rays coming from the reflector and rays directly falling on the absorber, as shown in Figure 13(ii). However, when the elevation angle is above $90-\beta$, the reflector will shade the absorber therefore the number of rays directly falling on the absorber will reduce as shown in Figure 13 (iii).

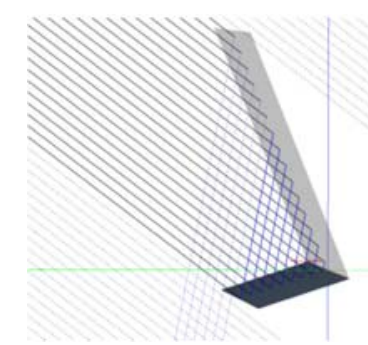

(i)

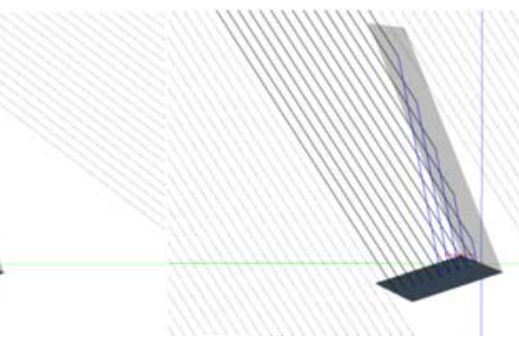

(ii)

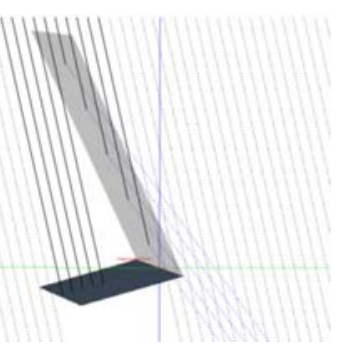

(iii)

Figure 13 Optical ray tracing at different elevation angles 
Based on this, and from geometry, an expression for the concentration ratio $C$ can be given by equation 3.

$$
C=\left\{\begin{array}{lc}
{\left[\frac{\cos (\alpha+\beta)(\tan (\alpha+\beta)+\tan \beta)}{\operatorname{Sin} \alpha}\right] \rho_{A l}+\frac{1}{\cos \beta}} & \alpha<(90-2 \beta) \\
{\left[\frac{\cos (\alpha+\beta)(3+\tan \beta)}{\operatorname{Sin} \alpha}\right] \rho_{A l}+\frac{1}{\cos \beta} \quad(90-2 \beta)<\alpha<(90-\beta)} \\
\frac{\sin \alpha(1-\tan (90-\beta))(\tan (\alpha-(90-\beta)))}{\sin (\beta+\alpha)} & (90-\beta)<\alpha<90
\end{array}\right.
$$

Now, to examine the influence of these optical characteristics across a year, there is a need to understand the variation in the sun's position across the year. Hence, to combine the concentration ratio with the solar elevation angle $\alpha$, the Sun Earth geometric relationship is used, where solar elevation angle $\alpha$ can be expressed in terms of latitude $(L)$, declination $\left(\delta_{s}\right)$ and the hour angle $\left(h_{s}\right)$ as given by equation 4 (Goswami et al. 2000).

$$
\alpha=\sin ^{-1}\left(\sin L \sin \delta_{s}+\cos L \cos \delta_{s} \cosh h_{s}\right.
$$

Here solar declination angle $\delta_{s}$ can be estimated by equation 5

$$
\delta_{s}=23.45 \sin \left(\frac{360(284+n)}{365}\right)
$$

Where $\mathrm{n}$ is the Julian day number.

The hour angle $\left(h_{s}\right)$ can be expressed in terms of the local solar time $(L S T)$ as given in equation 6 .

$$
h_{s}=15(L S T-12)
$$

Local solar time $L S T$ can be found in terms of local time (LT) and the time correction factor (TC) as given in equation 7.

$$
L S T=L T+\frac{T C}{60}
$$

In equation 7 the time correlation factor $T C$ can be given by equation 8 .

$$
T C=4(\text { longitude }-15(L T-G M T))+E T
$$

Here, the Greenwich Mean Time is denoted by GMT and ET is a correction factor given in minutes that accounts for the irregularity of the speed of earth's motion around the sun that can be expressed by equation 9.

$$
E T=9.87 \sin 2 b-7.53 \cos b-1.5 \sin b
$$

$\mathrm{b}$ is defined by equation 10 . 


$$
b=\frac{360(n-81)}{364}
$$

Finally, by combining equation 3 and 4 the concentration ratio of the collector at any time on a particular day can be calculated.

\subsection{Validation of the flat reflector model}

Having formulated an analytical expression that could be used to describe the optical characteristics of a flat reflector BIPVT concentrator, an experiment was conducted in order to validate the derived mathematical model. For the experiment, the absorber plate was assembled by placing standard silicon solar cells (156mm x 156mm) under a static reflector. The reflector (3M Solar Mirror Film 1100 on an aluminium backing sheet) was fixed to a supporting frame with an inclination of approximately $20^{\circ}$ to the vertical while the photovoltaic cells were placed at an angle of $20^{\circ}$ to the horizontal. Subsequently, a Delta-T SPN1 sunshine pyranometer $( \pm 5 \%)$ was mounted adjacent to the concentrator to measure the beam and diffuse radiation. The voltage generated by the photovoltaic absorber was measured simultaneously with the current, measured across a $1 \mathrm{~m} \Omega$ shunt resistor, in order to determine the power produced by the concentrator. A schematic representation of the experiment that was developed is shown in Figure 14.

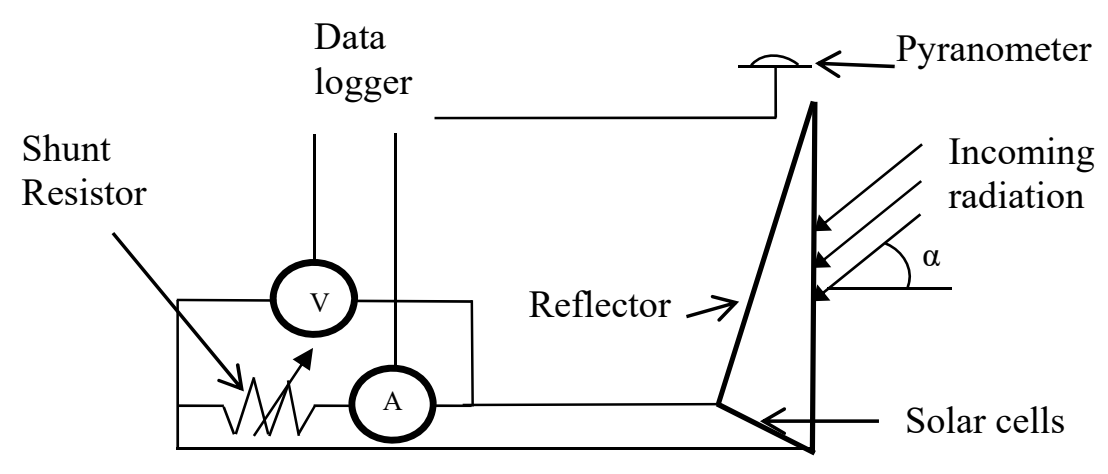

Figure 14 Schematic diagram of the test rig

Now, when radiation falls on a solar cell it produces a current proportional to the radiation falling on it, so to determine the concentration ratio, the current produced by the concentrator was compared with the current produced by a reference cell mounted adjacent to the concentrator. By finding the ratio between the short circuit current measured across the absorber and across the reference cell, the relative concentration ratio $C$ could be estimated.

To validate the optical model several sets of readings were taken from the test rig at various solar elevation angles. In order to do so, the readings were taken on different days over the year, when the sun was near solar noon to reduce the effect of shading due to the design of the mounting enclosure. As shown in Figure 15 the geometric model of the concentration ratio, including the solar elevation angle, is capable of predicting the concentration ratio with good accuracy. 


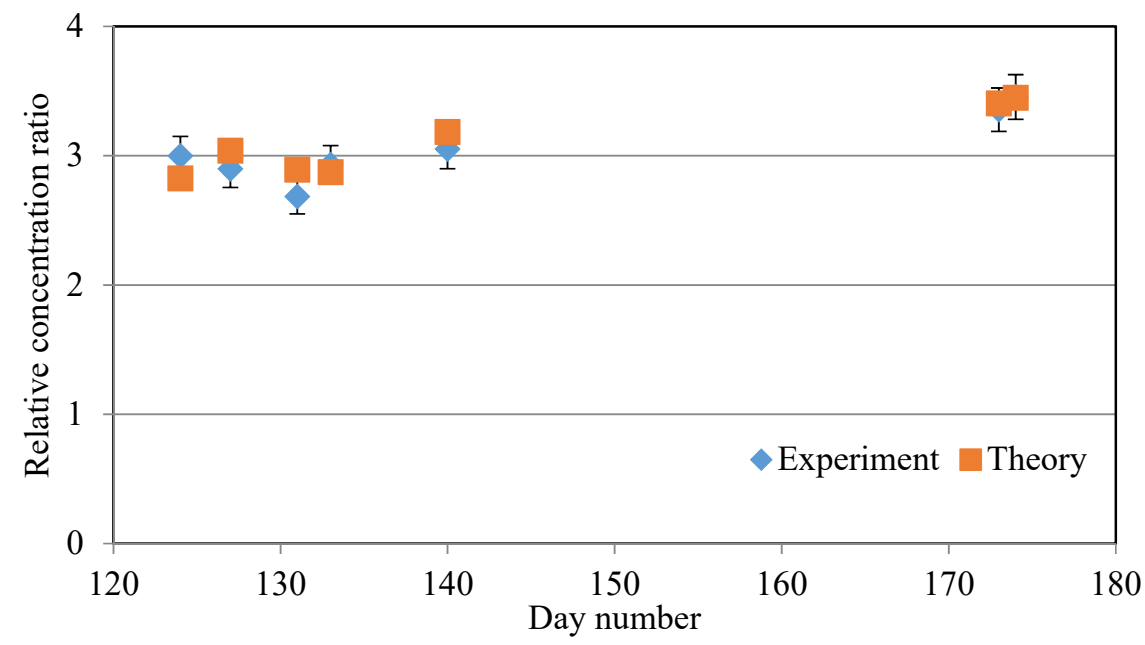

Figure 15 Experimental concentration ratio and calculated concentration ratio

\subsection{Flat reflector modelling results and analysis}

Having shown experimentally that the geometric model can be used to evaluate the performance of the collector, it was decided to examine its capabilities on any given day and time of the year. When the annual concentration ratio variation is plotted, as shown in Figure 16, the optical concentration ratio is higher during winter days with low solar elevation angles (for example day numbers 120-210) than during the summer period (for example day numbers 330-60) with a higher solar elevation angle. Similarly, for a given day, the concentration ratios in the morning and evening are again high due to low elevation angle of the sun while as noon approaches, the concentration ratio decreases.

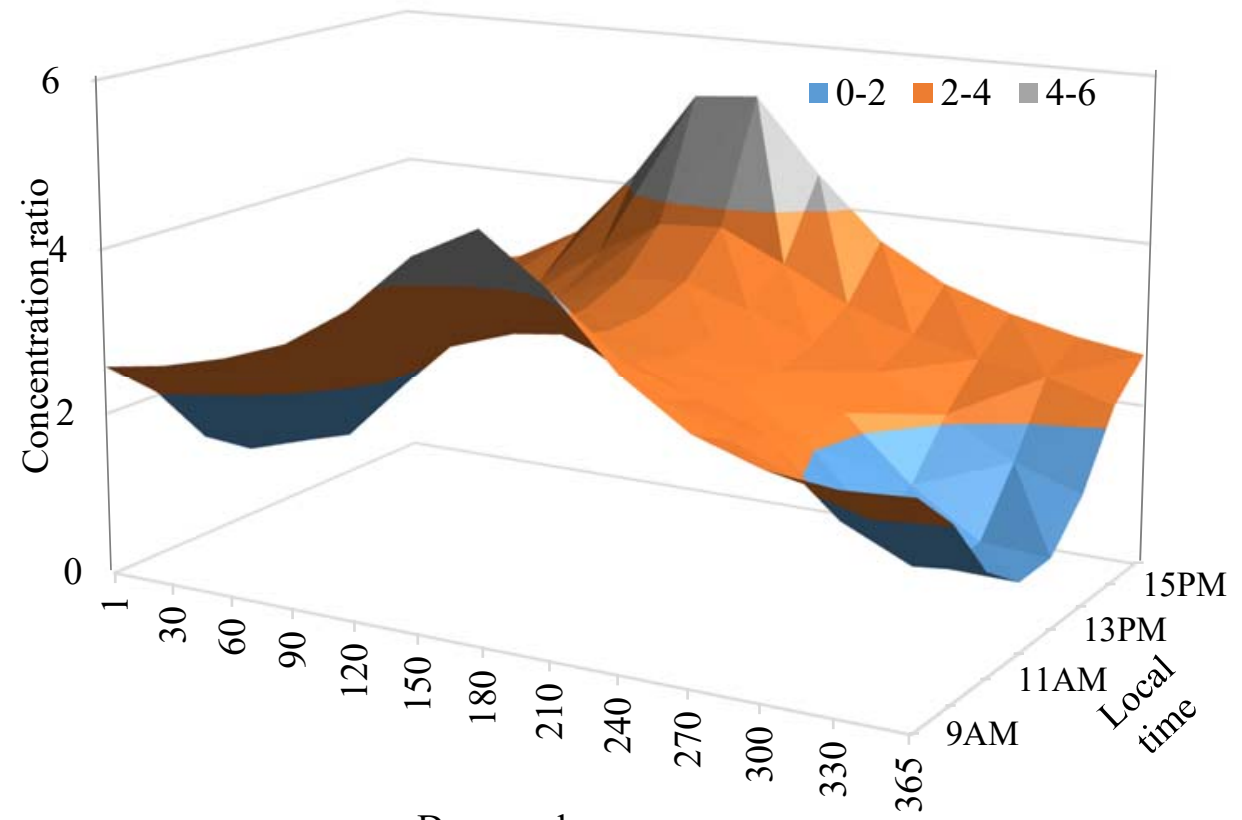

Day number

Figure 16 Concentration ratios over the year 
To illustrate this point, the total radiation reaching the absorber on a typical clear summer day (January 9 in Kaitaia, $-35.1^{\circ}, 173.3^{\circ}$ ) is shown in Figure 17. Here the total radiation falling on the absorber is high in the morning and the afternoon and the collector responds with higher concentrations, as the solar elevation angle is lower than that at midday. However, as the elevation angle of the sun approaches $75^{\circ}$ during the middle of the day, the reflector shades the absorber and reduces the radiation falling on it.

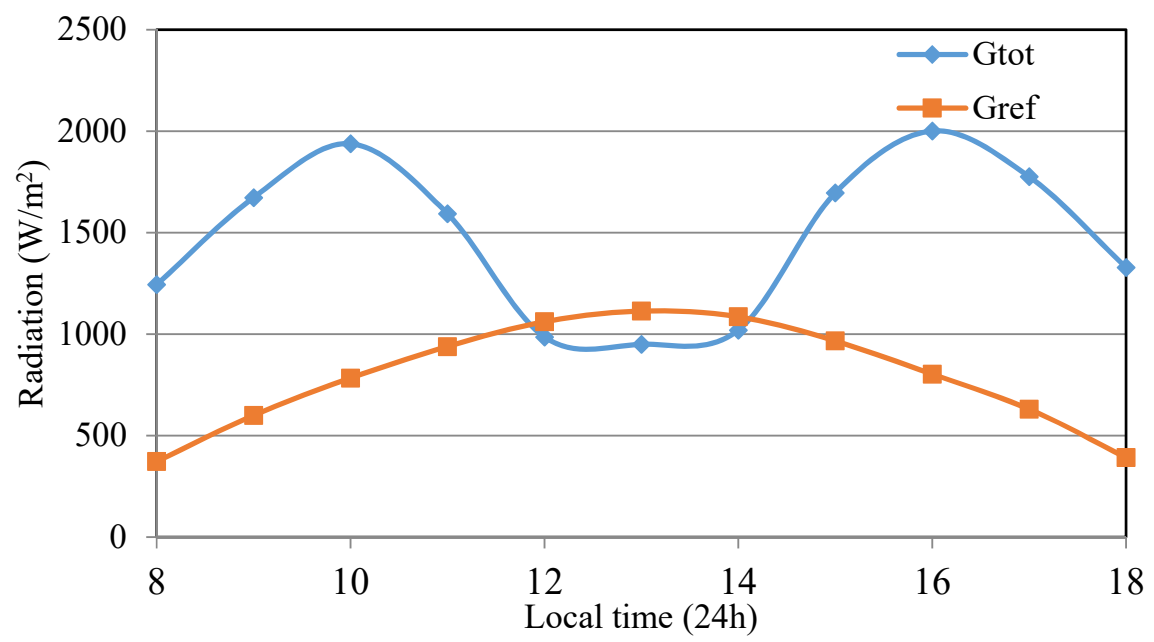

Figure 17 Change in radiation on absorber during summer

Notably though, as shown in Figure 18, the radiation falling on the absorber on a typical clear winter day (June 30 in Kaitaia) does not encounter shading from the reflector, as the sun elevation angle at solar noon is only $34^{\circ}$. Furthermore, it is important to note that, the reflector has increased the radiation falling on the absorber by at least 3 times throughout this winter day, and this highlights one of the major benefits of the flat reflector.

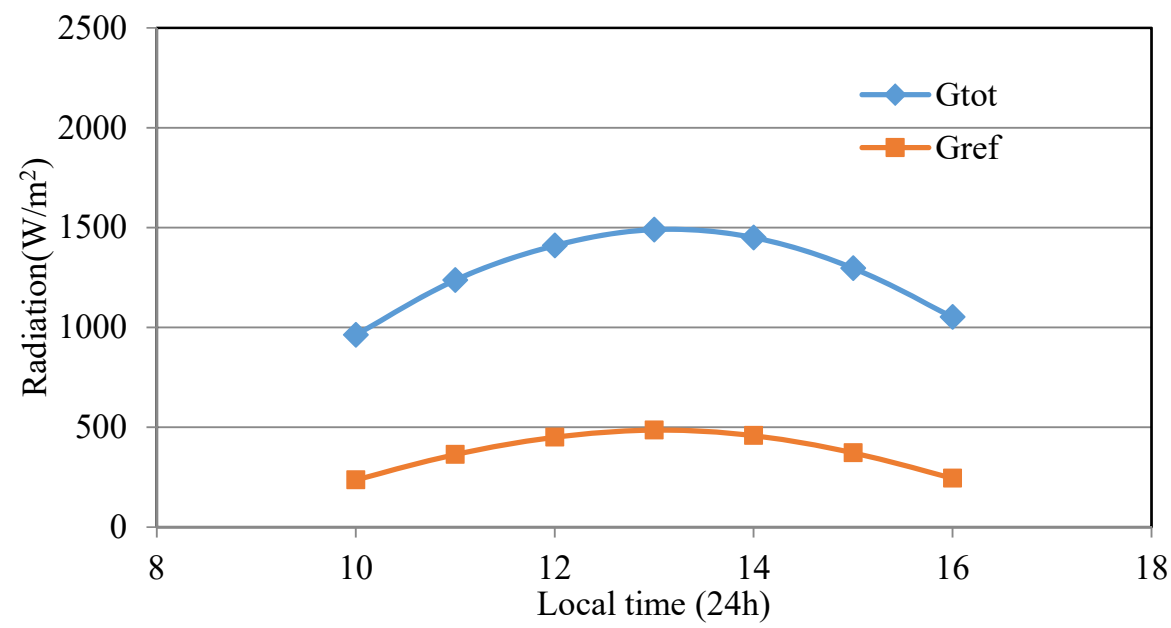

Figure 18 Change in radiation on absorber during winter

From the results, it was shown that the optical model incorporated with the Sun-Earth geometrical relationship presented in this section was able to calculate the total radiation falling on the absorber plate. Further, it was found that collector performance can be significantly improved during the winter 
days with lower elevation angle. This can potentially increase the performance of the collector significantly especially during the winter, spring and autumn seasons, possibly when energy is needed the most.

\section{Performance modelling of the BIPVT concentrator}

Having examined the optical design of the BIPVT concentrator and found a design suitable for façade integration it was decided to analyse the thermal performance of the proposed façade integrated collector shown in Figure 19. To achieve this, a one dimensional steady state thermal model was developed based on a simplified thermal resistance network as shown in Figure 20.

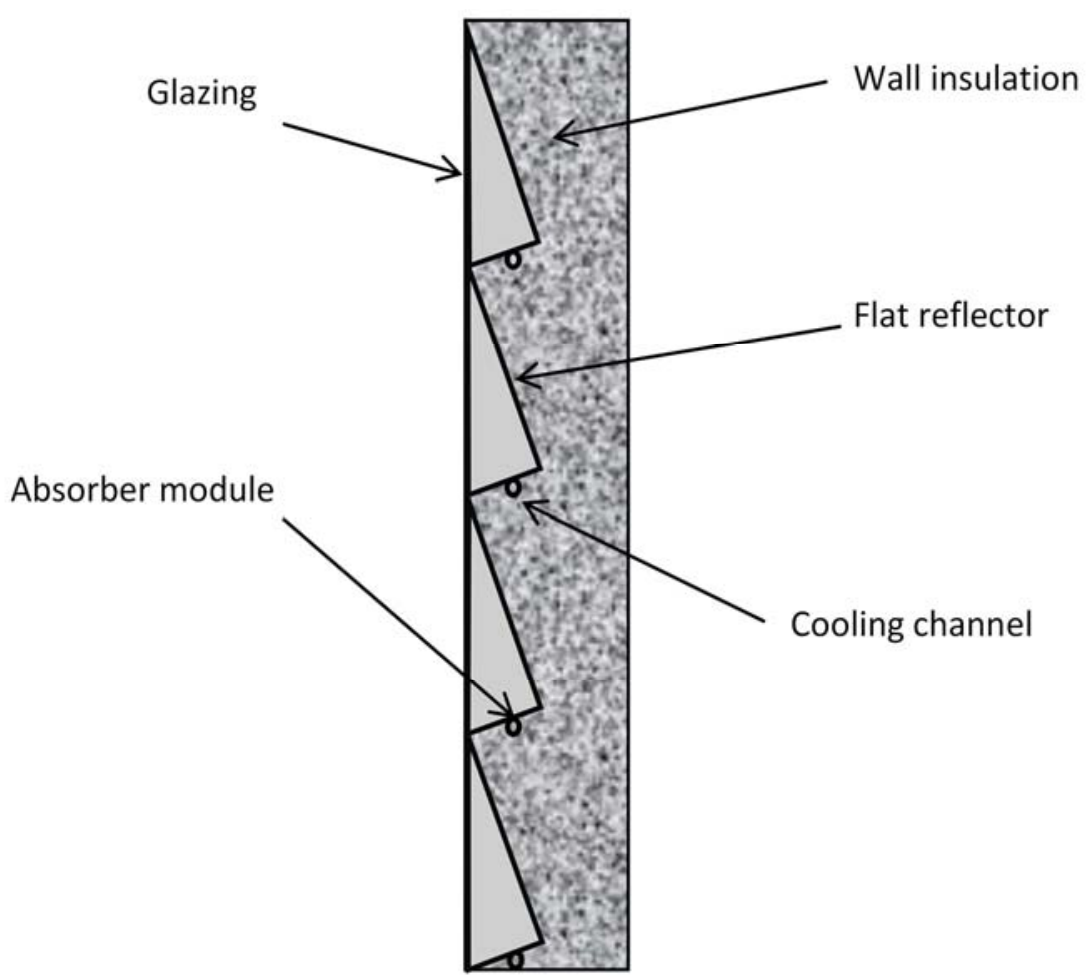

Figure 19 Façade Integrated Concentrator

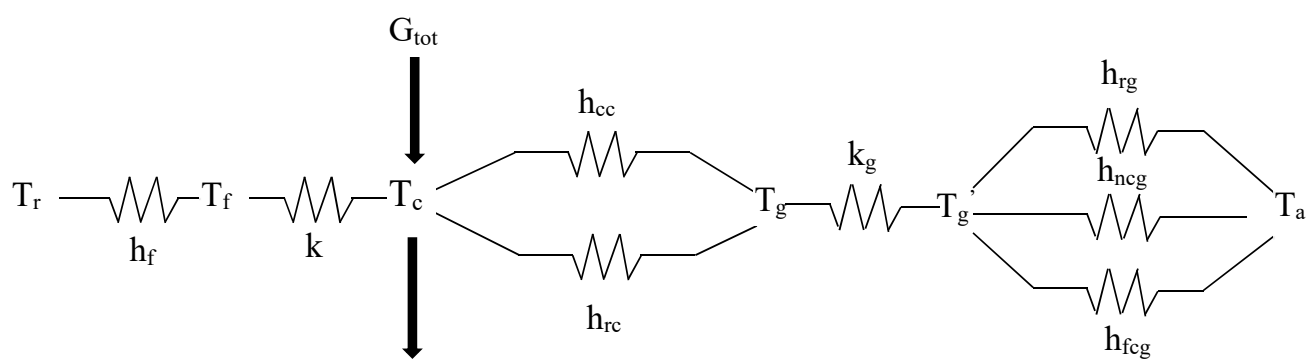

Collected energy

Figure 20 Simple thermal resistance network of the proposed module 
For a typical solar thermal collector, the useful thermal energy gain $Q$ can be determined from equation 11.

$Q=A F_{R}\left[(\tau \alpha)_{P V} G-U_{L}\left(T_{i}-T_{a}\right)\right]$

This equation can be further modified, as shown in equation 12, to incorporate the concentration ratio $C$ of the proposed low concentration collector.

$Q=A F_{R}\left[(\tau \alpha)_{P V} G . C-U_{L}\left(T_{i}-T_{a}\right)\right]$

where $Q$ is given by a function of the absorber area $(A)$, heat removal factor $\left(F_{r}\right)$, the transmittanceabsorptance product of the photovoltaic absorber $\left(\tau \alpha_{P V}\right)$, the solar radiation $(G)$, the concentration ratio $(C)$ is given by Equation 3, the overall heat loss coefficient $\left(U_{L}\right)$ and the temperature difference between inlet $\left(T_{i}\right)$ and the ambient temperature $\left(T_{a}\right)$.

In practice it is not possible to cover the whole absorber module with photovoltaic cells, hence equation 12 can be further modified to include a packing factor $(S)$ (the ratio of the area covered by PV cells to the total absorber area) and the transmittance-absorptance product of the thermal absorber $\left(\tau \alpha_{T}\right)$ and the PV material $\left(\tau \alpha_{P V}\right)$, as shown in equation 13 (Piratheepan, 2016).

$Q=S\left[A F_{R}\left[(\tau \alpha)_{P V} G . C-U_{L}\left(T_{i}-T_{a}\right)\right]\right]+(1-S)\left[A F_{R}\left[(\tau \alpha)_{T} G . C-U_{L}\left(T_{i}-T_{a}\right)\right]\right]$

The ratio of the heat collected for the irradiation falling on the absorber plate gives the thermal efficiency of the collector as shown in equation 14

$\eta_{\text {thermal }}=F_{R}\left[S(\tau \alpha)_{P V}+(1-S)(\tau \alpha)_{T}\right]-F_{R} U_{L} \frac{\left(T_{i}-T_{a}\right)}{G C}$

Furthermore, the collector heat removal efficiency factor $\left(F_{r}\right)$ can be expressed in terms of heat loss coefficient $\left(U_{L}\right)$, mass flow rate $(m)$ and the collector efficiency factor $\left(F^{\prime}\right)$ as given by equation 17 .

$F_{r}=\frac{m C_{p}}{A}\left[1-\exp ^{-\frac{A U_{L} F^{\prime}}{m C_{p}}}\right]$

The collector efficiency factor $\left(F^{\prime}\right)$ can be calculated using equation 18 in terms of its fin efficiency factor $F$.

$F^{\prime}=\frac{1 / U_{L}}{\left[\frac{1}{U_{L}[d+(w-d) F]}+\frac{1}{w h_{P V A}}+\frac{1}{\pi d h_{f l}}\right]}$

Here $h_{P V A}$ accounts for the bond resistance between the PV cell and the absorber plate as shown by (Zondag et al. 2002). The forced convection heat transfer coefficient $\left(h_{f l}\right)$ in the cooling tube can be determined from equation 19.

$h_{f l}=\frac{N u * k_{f l}}{d}$

Where $k_{f l}$ is the conductivity of the fluid at the mean temperature, $d$ is the hydraulic diameter of the tube and $N u$ is the Nusselt number that can be determined from any number of relationships for forced convective heat transfer in a tube, in this study the Gnielinski (Cengel 2007) correlation was used. 
In order to calculate the fin efficiency factor $(F)$, it is necessary to calculate the coefficient $(M)$ that accounts for the overall thermal conductivity and the thickness of the PVT absorber plate as given by equation 20 in terms of overall thermal loss coefficient $\left(U_{L}\right)$.

$M=\sqrt{\frac{U_{L}}{K_{a b s} L_{a b s}+K_{P V} L_{P V}}}$

As such, the modified fin efficiency $(F)$ can be calculated using equation 21, where $w$ is the tube spacing (or the absorber width for a single tube absorber) and $d$ is the hydraulic diameter of the tube.

$F=\frac{\tanh \left[\frac{M(w-d)}{2}\right]}{\frac{M(w-d)}{2}}$

In the determination of $M$ in equation 20, the overall thermal loss coefficient $\left(U_{L}\right)$ is the sum of the heat losses via top, rear and edge of the collector as given by equation 22 .

$U_{L}=U_{\text {top }}+U_{\text {rear }}+U_{\text {edge }}$

As the rear heat loss and edge losses are through the insulation, the rear loss coefficient $\left(U_{\text {rear }}\right)$ and the edge loss coefficient $\left(U_{\text {edge}}\right.$ ) can be determined from Fourier's Law using the thickness and thermal conductivity of the insulation and the outer wall (though typically heat loss by these paths is relatively small).

However, in the determination of the top losses the glazing on the proposed collector, as shown in Figure 19, is not parallel to the absorber plate. Recently though, Piratheepan and Anderson (2015) showed that the natural convection heat loss in an air filled enclosure such as this could be predicted by equation 23, where $b$ is the breadth of the absorber and $h$ is the height of the reflector.

$$
N u=0.67 R a^{0.36}(b / h)^{1.75}
$$

This can subsequently be rearranged to determine the value of the natural convection heat transfer coefficient $h_{c c}$ inside the concentrator enclosure as given in equation 24 .

$h_{c c}=\left(\frac{k}{b}\right) 0.67 R a^{0.36}(b / h)^{1.75}$

To estimate the radiation heat transfer coefficient inside the concentrator $h_{r c}$ the enclosure was assumed to be a two-surface enclosure consisting of the absorber plate and the glazing by assuming the reflector is adiabatic. Hence an expression for $h_{r c}$ can be written in terms of area of the absorber plate $(A)$, area of the glazing $\left(A_{g}\right)$, the view factor $\left(F_{c g}\right)$ from the absorber to the glazing, and the emittance of absorber plate and the glazing $\varepsilon_{p}$ and $\varepsilon_{g}$, as shown in equation 25 .

$h_{r c}=\frac{\sigma\left(T_{p m}^{4}-T_{g}^{4}\right)}{\left(\frac{1-\varepsilon_{c}}{A \varepsilon_{c}}\right)+\left(\frac{1}{A F_{c g}}\right)+\left(\frac{1-\varepsilon_{g}}{A_{g} \varepsilon_{g}}\right)}$

Where $T_{p m}$ and $T_{g}$ are the mean plate temperature and the internal glazing temperature of the collector respectively.

The view factor $F_{c g}$ can be deduced from equation 26 in terms of the enclosure dimensions

$F_{c g}=\frac{2 b}{b\left(1+\frac{1}{\sin \beta}\right)-h}$ 
Subsequently, the heat loss through the glass cover can be calculated using the heat transfer coefficient of the glass $k_{g}$ internal glazing temperature $T_{g}$ and external glazing temperature $T_{g}$.

Now, the external heat loss from the glazed cover is the sum of the radiation, natural and the forced convection heat losses. As majority of the collector faces the ambient environment, it was assumed that the glass cover radiated heat to the surroundings with an ambient temperature $T_{a}$. Hence, the radiation heat transfer coefficient from the glazing $h_{r c g}$ can be expressed in terms of external glazing temperature $T_{g}{ }^{\prime}$ and the ambient temperature $T_{a}$ as shown in equation 27.

$h_{r c g}=\sigma \varepsilon_{g}\left(T_{g}^{\prime 2}+T_{a}^{2}\right)\left(T_{g}^{\prime}+T_{a}\right)$

Furthermore, the losses due to natural and forced convection also must be taken in to account. The forced convection heat transfer coefficient $h_{f c g}$ will be a function of velocity of the wind, an approximation of which can be expressed by equation 28, where $V$ is the wind velocity (Eicker, 2006). $h_{f c g}=4.214+3.575 \mathrm{~V}$

The natural heat transfer coefficient $h_{n c g}$ can be expressed by equation 29 (Eicker, 2006).

$h_{n c g}=1.78\left(T_{g}^{\prime}-T_{a}\right)^{1 / 3}$

Using this approximation, it is possible to calculate the overall convection heat transfer coefficient $h_{c}$ by integrating both forced and natural heat transfer coefficient using equation 30 (Eicker 2006).

$h_{c}=\left(h_{f c g}^{3}+h_{n c g}^{3}\right)^{1 / 3}$

In summary; the combination of heat losses and the total useful energy extracted, considering the energy balance of the collector, mean the thermal efficiency of the façade integrated collector can be established.

In examining the performance of the system, it is possible to utilise the knowledge of the thermal performance to determine the electrical performance. In this regard, one trade-off of using silicon solar cells under concentrated radiation is that their efficiency degrades with the temperature increase. Hence it is essential to express the electrical efficiency in terms of the temperature of the absorber plate.

In exploring this the electrical power generated by the cell is given by the product of the current $\left(I_{m p}\right)$ and voltage $\left(V_{m p}\right)$ at its maximum power point, as shown in equation 31.

$P=I_{m p} V_{m p}$

This can also be expressed in terms of fill factor $(F F)$ and the open circuit voltage $\left(V_{o c}\right)$ and short circuit current $\left(I_{o c}\right)$ as shown in equation 32.

$P=F F I_{s c} V_{o c}$

However, $V_{o c}$ and $F F$ decrease significantly with increased temperature, while short circuit current increases marginally with the temperature (Zondag 2008). Taking this into account gives a good approximation of the electrical efficiency of a photovoltaic cell under various temperatures $\left(\eta_{e}\right)$ given that the nominal operating cell temperature (NOCT) (Dubey et al. 2013). The efficiency of the cell at NOCT conditions are known from the manufacturer's datasheet and for typical crystalline Si modules 
$\beta$ can be assumed as 0.004 (Notton et al. 2005). In this respect, when the packing factor $S$ is taken in to account, the electrical efficiency of the collector on a relative area basis $\eta_{\text {elect }}$ can be expressed by equation 33.

$\eta_{\text {elect }}=\eta_{\text {NOCT }}\left(1-\beta\left(T_{p m}-N O C T\right)\right) * S$

By combining equation 14 and equation 33 the combined efficiency $\eta_{t o t}$ of the collector can be calculated from equation 34 .

$\eta_{\text {tot }}=\eta_{\text {thermal }}+\eta_{\text {elect }}$

\subsection{Experimental method}

In order to validate the mathematical model and findings derived from its use, it is necessary to compare the outcome with an experimental prototype. As there is no standard method for testing photovoltaic/thermal hybrid modules it was decided use a standard steady state test method similar to that given in AS/NZS 2535.1 (2007) for determining the thermal performance of glazed liquid heating collectors. As such, an experimental testing system was constructed on the roof of Auckland University of Technology's School of Engineering building $\left(-36.8^{\circ}, 174.7^{\circ}\right)$, facing true north. In doing this, Ttype thermocouples $\left( \pm 0.3^{\circ} \mathrm{C}\right)$ were used to measure the inlet and the outlet of the coolant as well as the ambient temperature. A cup anemometer and a wind vane were mounted adjacent to the collector to measure the wind speed and direction. Finally, a Delta-T SPN1 type sunshine pyranometer was used to measure the radiation incident on a plane parallel to the absorber. For the electrical output, the voltage and current were measured simultaneously while keeping the system loaded at its maximum power point.

Fabricating the façade collector (as shown in Figure 19) involves three main parts; the PVT absorber, the reflector and the insulation elements including the glass cover. For this work two finned tube absorbers were fabricated from $1.2 \mathrm{~m}$ lengths of $2 \mathrm{~mm}$ thick aluminium, painted matte black. A single $10 \mathrm{~mm}$ square aluminium tube was attached to the back of each absorber using a thermally conductive adhesive to act as the cooling channel. Square tube was used as it provides a larger contact surface between the absorber plate and the cooling tube, thus improving the fin efficiency. Each absorber plate was then fitted with a custom made string of seven $150 \mathrm{~mm}$ mono-crystalline solar cells connected in series and bonded to the absorber using a silicone conformal coating. This thin layer of clear conformal coating protects the cells under extreme environmental and climatic condition and insulates the rear wiring of the solar cells when the absorber is exposed to the concentrated radiation. As described previously, a reflector was prepared by attaching 3M Solar Mirror Film 1100 to an aluminium backing sheet.

Due to the practical issues associated with integrating the façade integrated collector into an actual building façade, two vertical "wall" sections were fabricated to mount the concentrators. Each wall was packed with mineral wool insulation (R2.8) to insulate the rear of the concentrator, and replicate a 
building façade, while the front surface was glazed using a low-iron glass cover. A schematic representation of the combined collector test system is shown in Figure 21.

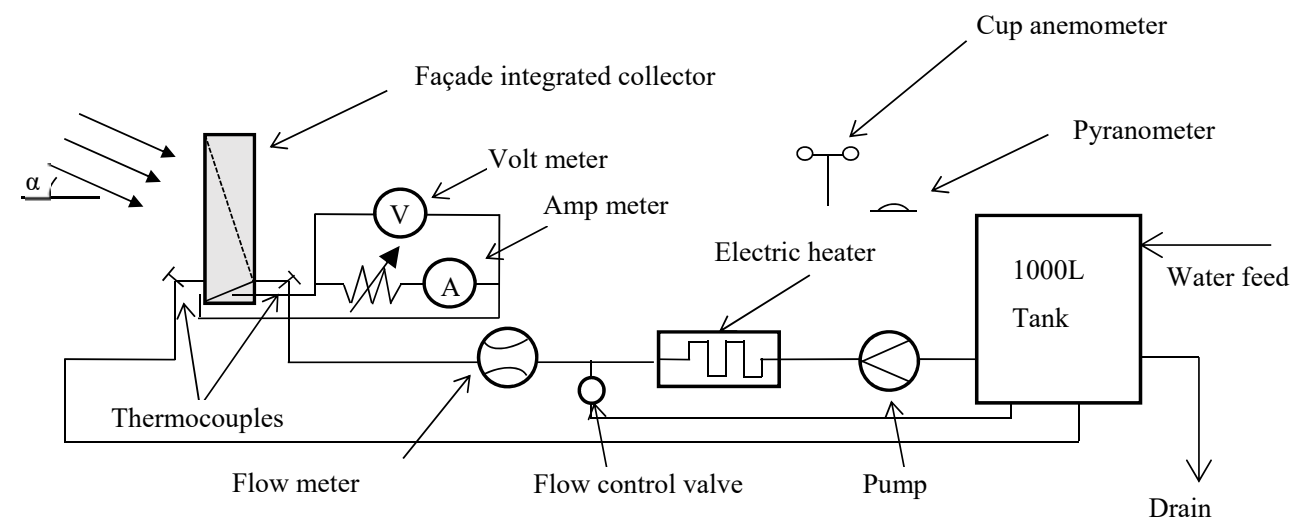

Figure 21 Experimental test rig and the circuit diagram for electrical measurements

In summary, the design parameters of the prototype collector tested are given in Table 1.

Table. 1: Physical characteristics of experimental prototype

\begin{tabular}{|c|c|c|c|}
\hline Parameter & Symbol & Value & Unit \\
\hline System flow rate & $\mathrm{m}$ & 0.8 & $\mathrm{l} / \mathrm{min}$ \\
\hline Absorber length & $\mathrm{L}$ & 2.4 & $\mathrm{~m}$ \\
\hline Absorber breadth & $\mathrm{b}$ & 0.2 & $\mathrm{~m}$ \\
\hline Reflector height & $\mathrm{h}$ & 0.6 & $\mathrm{~m}$ \\
\hline Collector area & $\mathrm{A}$ & 0.48 & $\mathrm{~m}^{2}$ \\
\hline PV Transmit/apsorpt & $\tau \alpha_{\mathrm{PV}}$ & 0.8 (Anderson 2009) & - \\
\hline Thermal Transm/apsorpt & $\tau \alpha_{\mathrm{T}}$ & 0.87 (Anderson 2009) & - \\
\hline Absorber thickness & $\mathrm{L}_{\mathrm{abs}}$ & 0.002 & $\mathrm{~m}$ \\
\hline PV thickness & $\mathrm{L}_{\mathrm{PV}}$ & 0.0004 & $\mathrm{~m}$ \\
\hline PV conductivity & $\mathrm{K}_{\mathrm{PV}}$ & 130 & $\mathrm{~W} / \mathrm{mK}$ \\
\hline Tube hydraulic diameter & $\mathrm{d}$ & 0.0088 & $\mathrm{~m}$ \\
\hline Tube spacing & $\mathrm{W}$ & 0.2 & $\mathrm{~m}$ \\
\hline $\begin{array}{c}\text { Cell-absorber Quasi heat } \\
\text { transfer coefficient }\end{array}$ & $\mathrm{h}_{\mathrm{PVA}}$ & $45($ Zondag et al. 2002) & $\mathrm{W} / \mathrm{m}^{2} \mathrm{~K}$ \\
\hline Insulation conductance & $\mathrm{k}_{\text {ins }}$ & 0.045 & $\mathrm{~W} / \mathrm{mK}$ \\
\hline Back insulation thickness & $\mathrm{L}_{\mathrm{ins}}$ & 0.1 & $\mathrm{~m}$ \\
\hline Edge insulation thickness & $\mathrm{L}_{\mathrm{edge}}$ & 0.025 & $\mathrm{~m}$ \\
\hline Absorber conductivity & $\mathrm{K}_{\mathrm{abs}}$ & 130 & $\mathrm{~W} / \mathrm{mK}$ \\
\hline Packing factor & $\mathrm{S}$ & 0.7 & - \\
\hline Conductance of glass & $\mathrm{k}_{\mathrm{g}}$ & 0.9 & $\mathrm{~W} / \mathrm{mK}$ \\
\hline Reflectance of silver metalized & $\rho_{\mathrm{Al}}$ & 0.9 & - \\
\hline film & & & \\
\hline
\end{tabular}




\subsection{Experimental validation of the thermal model}

To validate the mathematical model, the test rig was fed with hot water at different temperatures from an electric heater. The beam radiation on a horizontal surface, mass flow rate of the water, input-output temperatures of the water at the entrance and the exit of the collector, the ambient temperature and the wind speed were also measured. These were taken when the sun was near solar noon, such that the effect of shading, due to the design of mounting enclosure, was minimised. Furthermore, in order to find the electrical output, the current and the voltage was also measured at maximum power point by measuring the voltage signal across the collector using a dynamic load. Finally, the combined efficiency was calculated by taking the ratio of the electrical and thermal output, to the total solar radiation incident on the absorber $\left(G^{*} C\right)$.

As shown in Figure 22 the mathematical model incorporating the new heat transfer relationship for the concentrator (Piratheepan and Anderson, 2015) and the concentration ratio, is capable of predicting the performance with reasonable accuracy.

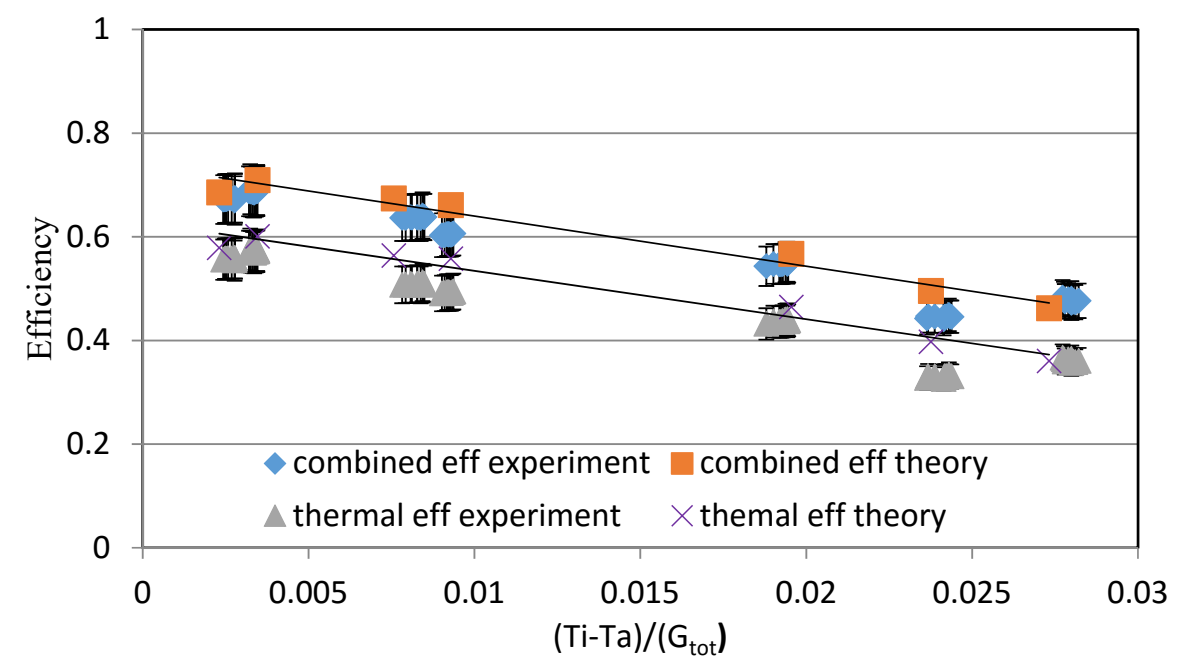

Figure 22 Experimental and theoretical efficiencies of façade integrated collector

\subsection{Thermal modelling results and analysis}

Now in Table 1, there are number parameters that could be modified to improve the performance of the collector. In order to find out the critical design variables, the mathematical model was used to perform a sensitivity analysis on the system. Where possible, only one design variable was varied at a time and the effect of that particular parameter on the efficiency was observed. This allows us to determine the design variables that are critical in terms of efficiency of the system and its design.

In the concentrator it is likely that high temperatures will be achieved and so there is a need for improved cooling. Heat transfer in the cooling channel is a function of Reynold's number and thus varying the flow rate may have the effect on the overall efficiency of the collector. However as shown on Figure 23 , the efficiency of the collector does not significantly improve with the increased fluid flow rate. The slight increase in efficiency can be attributed to an increase in the turbulence in the system increasing 
the heat transfer marginally. Furthermore, a reduction in temperature will increase the electrical efficiency marginally, though the pumping power required to achieve this may offset any gains.

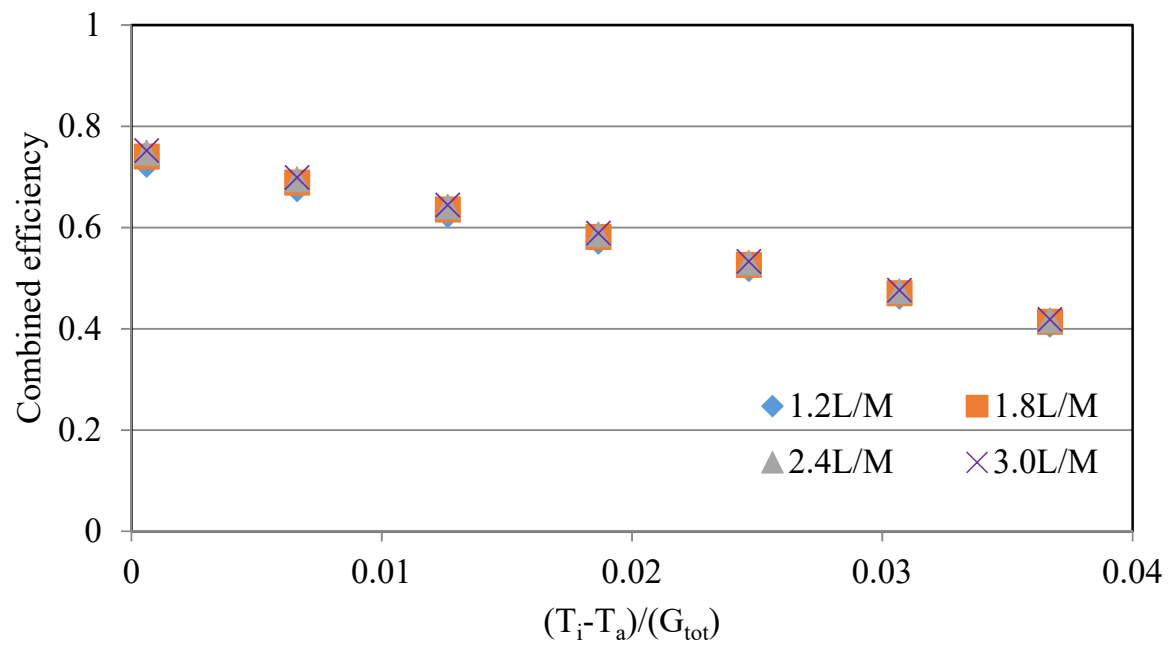

Figure 23 Combined efficiency by varying flow rate

Another means of improving the efficiency could be to reduce the width of the absorber for a single tube, or by decreasing the spacing between adjacent tubes in systems with multiple cooling tubes. As shown in Figure 24, this will increase the efficiency significantly. This can be explained by the fact that an increase in the number of tubes across the absorber plate improves the fin efficiency and thus increases the performance of the collector. However, it can be seen that, at higher (Ti-Ta) $/ G^{*} C$ values they tend to converge. This suggest that although decreasing the tube spacing increases the efficiency initially, there are other factors which will decrease the efficiency at higher $(T i-T a) / G^{*} C$.

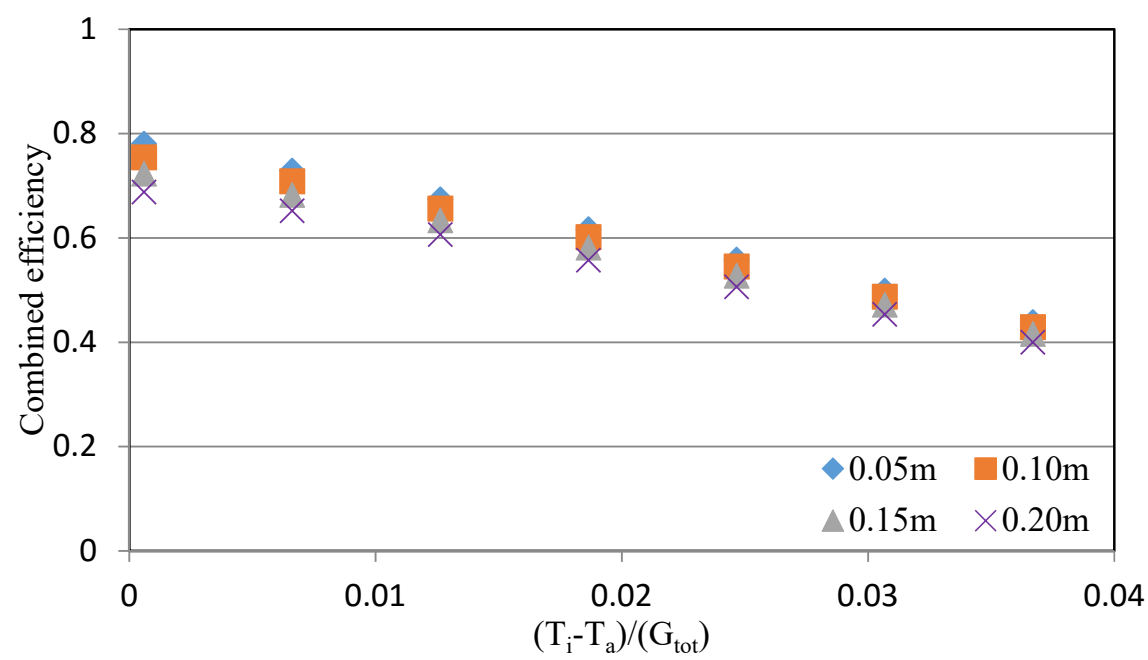

Figure 24 Combined efficiency by varying tube spacing

Further, the combined efficiency of the collector could be also improved by improving the heat transfer coefficient between the solar cells and the thermal absorber. Unlike a thermal collector that has a bond resistance between the tube and absorber (Duffie and Beckman 2006), a "quasi" heat transfer coefficient, with a value of $45 \mathrm{~W} / \mathrm{m}^{2} \mathrm{~K}$, between the PV cells and the absorber plate is used (Zondag et 
al. 2002). Based on this Anderson et al (2009) stated that this thermal conductance might be improved by means introducing a thermally conductive adhesive. Following on from this recommendation, in Figure 25 it can be seen that when the heat transfer coefficient is doubled from $30 \mathrm{~W} / \mathrm{m}^{2} \mathrm{~K}$ to $60 \mathrm{~W} / \mathrm{m}^{2} \mathrm{~K}$ the efficiency is improved by approximately $10 \%$.

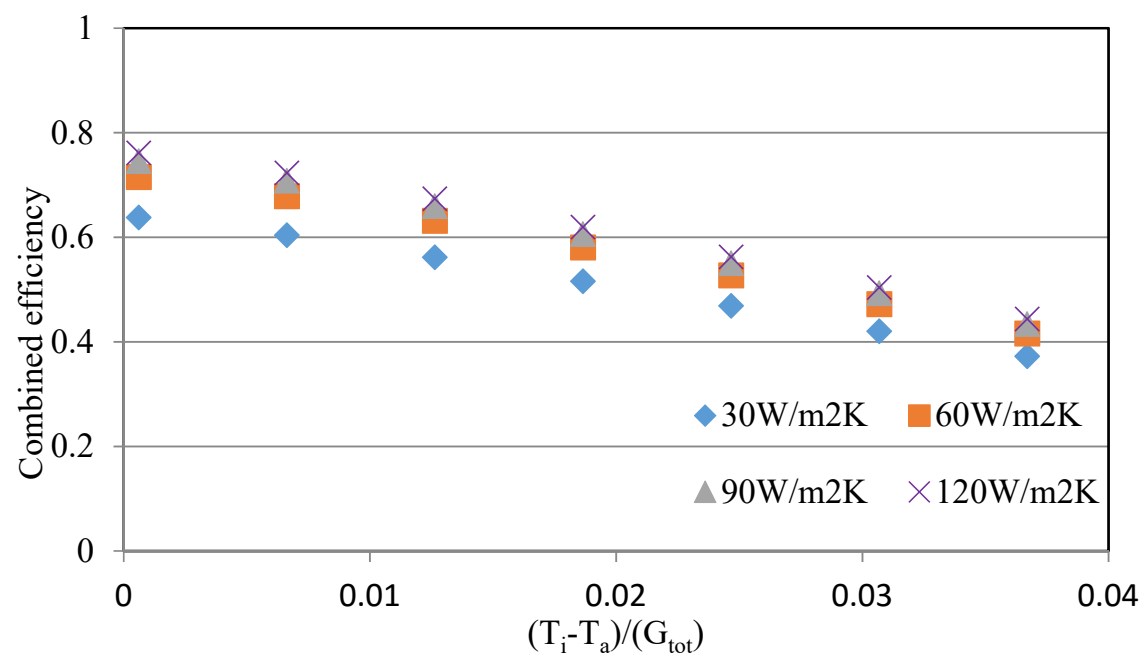

Figure 25 Combined efficiency by varying cell to absorber heat transfer coefficient

It is also important to see how, the packing factor of the solar collector (accounts for the ratio of the area covered by PV solar cells out of total area of the absorber) influence its efficiency due to the low thermal absorptance of the silicon cells $\left(\tau \alpha_{P V}\right)$. As shown on Figure 26, the thermal efficiency of the collector decreases with the PV cell coverage. However, as shown in Figure 27, although the thermal efficiency of the collector decreases significantly with the packing factor, the overall efficiency of the collector increased marginally. This shows that covering the thermal absorber with the PV cells will increase the overall efficiency thus compensating for the thermal efficiency reduction.

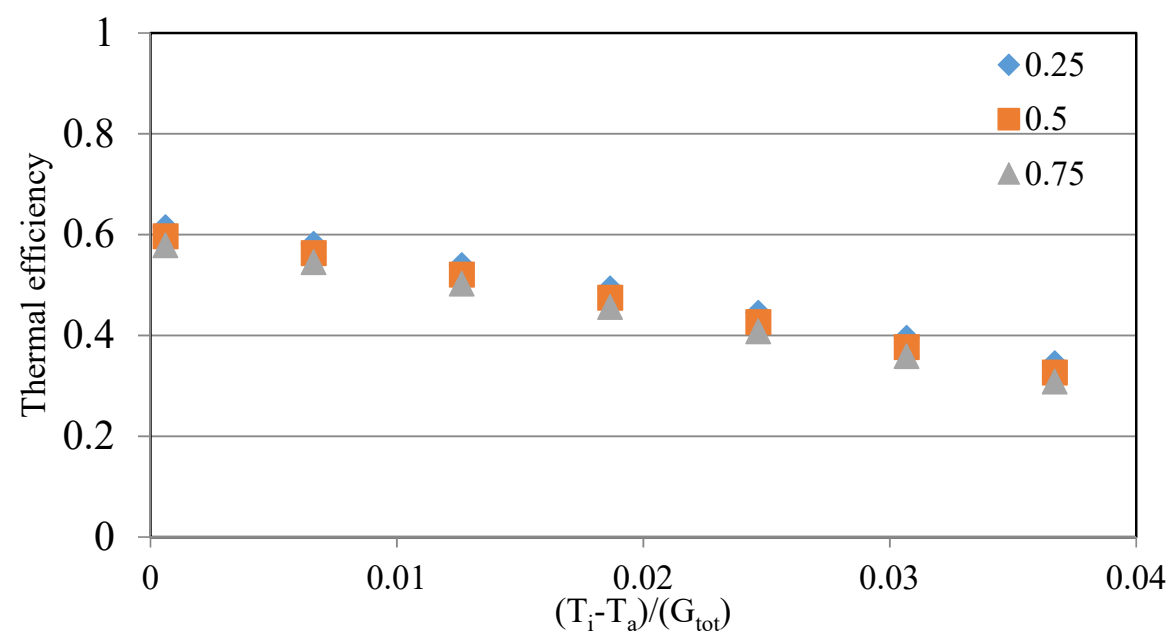

Figure 26 Thermal efficiency varying packing factor 


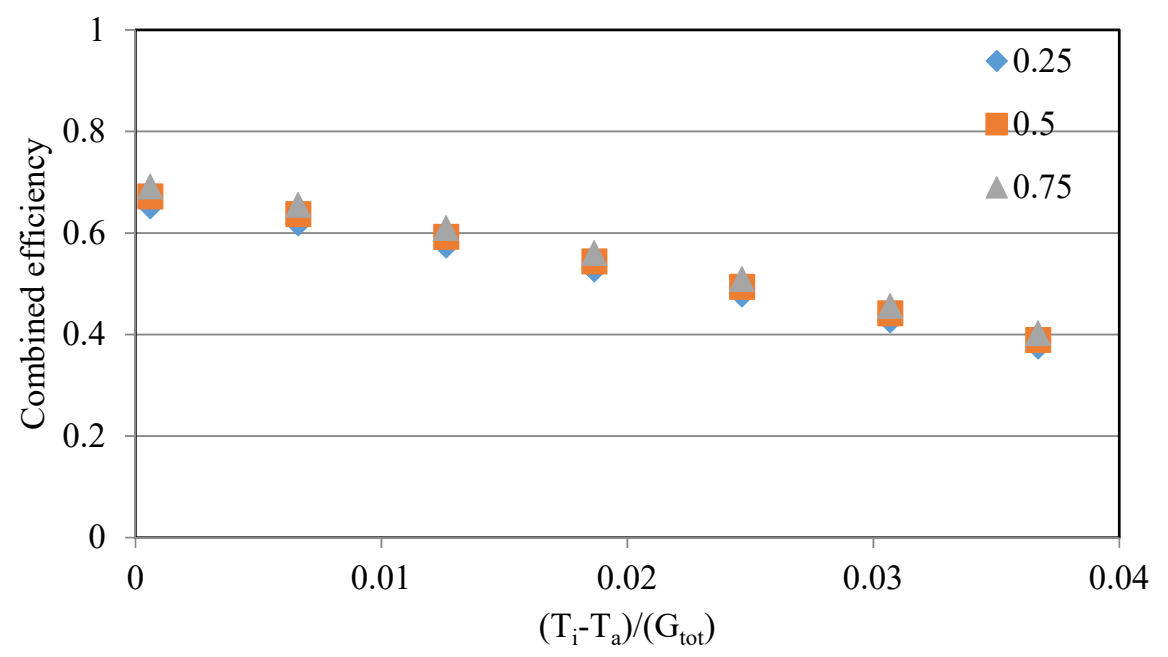

Figure 27 Combined efficiency varying packing factor

To understand the effect of reflector reflectance for different scenarios, the electrical output of the collector was modelled for a sunny day using data for Kaitaia, New Zealand.. As shown in Figure 28 the output of the collector increases with the reflector's reflectance. It is important to note that, the performance of the collector strongly depends on the reflector reflectance, and reduction in reflectance will reduce the output of the collector dramatically.

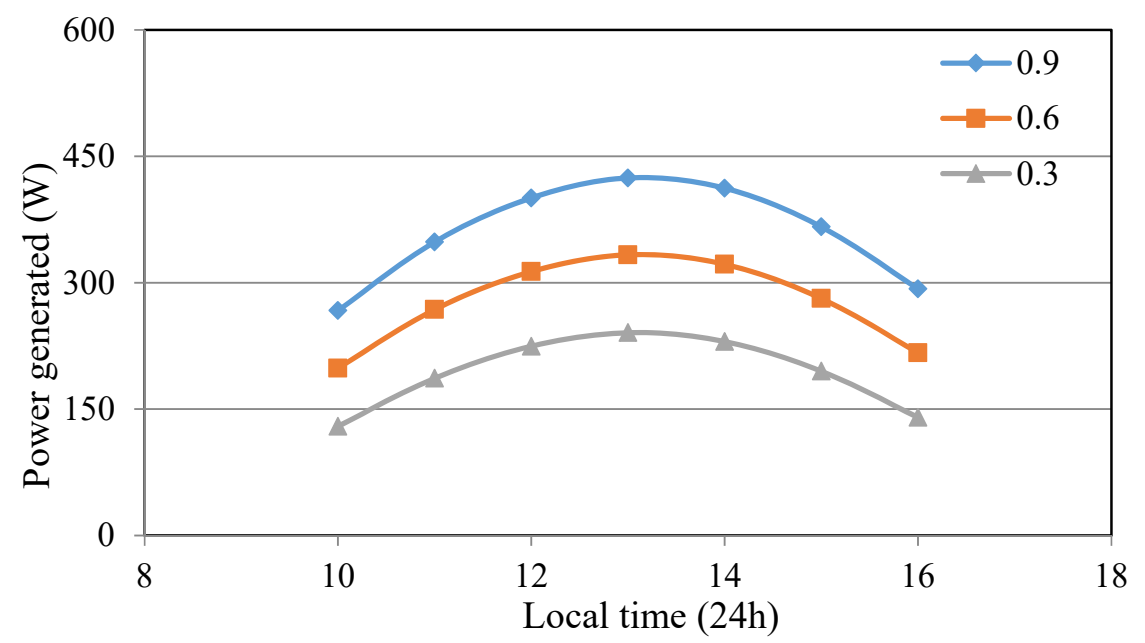

Figure 28 Performance of the collector varying the reflectance of the reflector

Exploring this further, the electrical output of the collector was analysed for a typical sunny summer and winter day in Kaitaia. As shown in Figure 29, the output of the collector increases before $12 \mathrm{pm}$ and after $2 \mathrm{pm}$, peaking at 10 am and $4 \mathrm{pm}$ compared to an absorber without a concentrating element (this behaviour is due to shading of the reflector as described previously). During the summer the collector will produce more power at lower elevation angles, coincidently this is the time a typical house has higher power demand. 


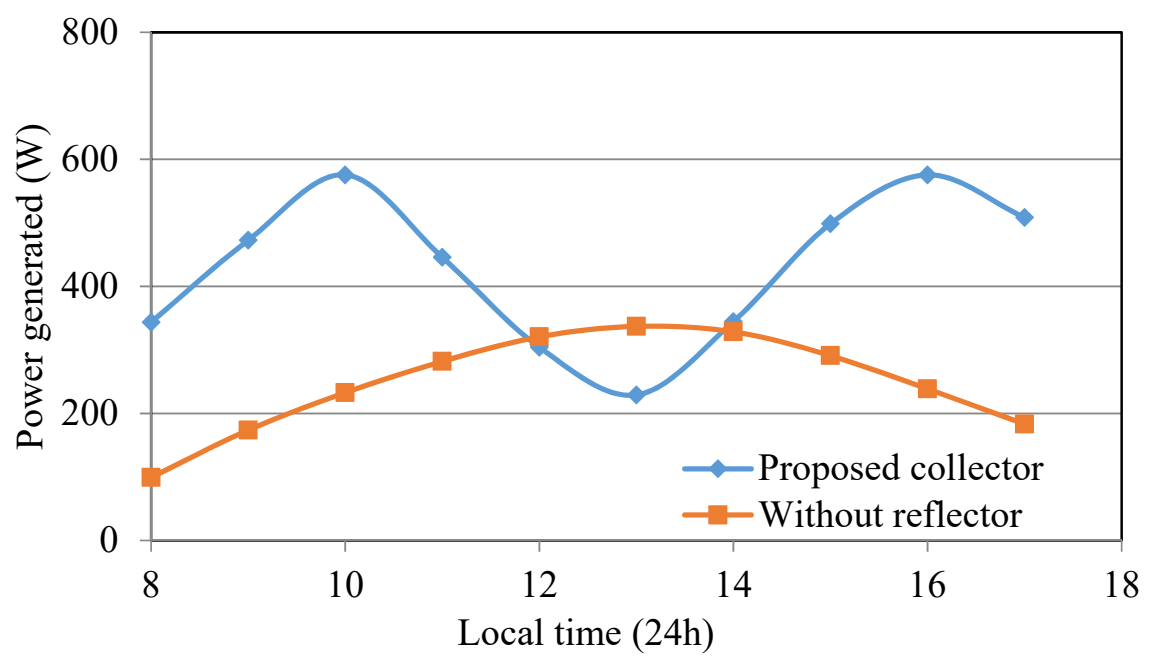

Figure 29 Performance of the collector on 9th of January

Likewise, in winter, the performance of the collector compared to the absorber without the concentrating element, improves dramatically throughout the day, as shown in Figure 30.

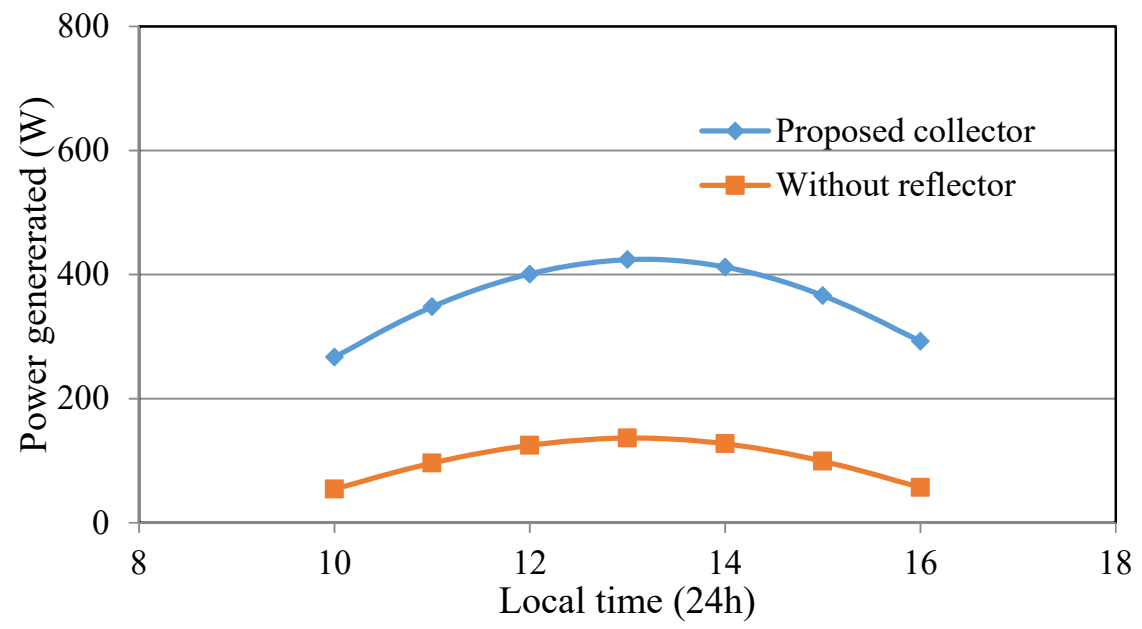

Figure 30 Performance of the collector on 30th of June

In this respect it demonstrates the potential for a combination of roof top collectors, with low concentration ratio façade integrated solar collectors, and this may well be a step towards net zero energy buildings.

\section{Conclusion}

From this work, there are number of conclusions that can be drawn with regard to the design and operation of BIPVT concentrators for façade integration; firstly, increasing the flowrate in the cooling tubes appears to offer little benefit with respect to increasing the efficiency of the collector. However, the combined efficiency of the collector can be improved by increasing the number of cooling channels across the absorber plate, though this may not be economical. Hence increasing the number tubes has 
to be considered as a trade-off between the efficiency and the cost of the collector. Furthermore, improved thermal contact between the solar cells and the thermal absorber will increase the efficiency to a greater extent and appears to offer significant potential in improving the performance of the façade integrated BIPVT solar concentrator system.

More importantly, the output of the collector appears to be heavily dependent on the reflectance of the reflector. Hence it is important to have a quality reflector that can keep its reflectance throughout the lifetime of the collector. Finally, the façade integrated collector performs well under moderate and low elevation angles, which often corresponds to times of peak electrical demand and would appear to be well suited to operating in combination with the roof mounted collectors.

\section{Acknowledgement}

This is an extension of work presented at the ISES Solar World Congress 2015.

\section{References}

Anderson, T.N., 2009, Investigation of thermal aspects of building integrated photovoltaic/thermal solar collectors, $\mathrm{PhD}$ Thesis, University of Waikato

Anderson, T.N., Duke, M., Morrison, G.L. and Carson, J.K., 2009, "Performance of a building integrated photovoltaic/thermal (BIPVT) solar collector", Solar Energy, Vol. 83, pp. 445-455

AS/NZS 2535.1, 2007. Test methods for solar collectors. Part 1: thermal performance of glazed liquid heating collectors including pressure drop. Standards Australia, Homebush.

Brogren, M., 2004, "Optical efficiency of low-concentrating solar energy systems with parabolic reflectors" $\mathrm{PhD}$ thesis, Uppsala University, Uppsala.

Brogren, M. and Karlsson, B., 2002, "Low concentrating water cooled PV-thermal hybrid systems for high latitudes". Proceedings of Photovoltaic Specialists Conference, 2002, pp. 1733-1736

Cengel, Y. A. 2007, “Heat \& mass transfer: a practical approach”, McGraw-Hill, New York

Dubey, S., Sarvaiya, J.N., and Seshadri, B., 2013, “Temperature Dependent Photovoltaic (PV) Efficiency and Its Effect on PV Production in the World - A Review", Energy Procedia, Vol 33, pp. 311-321

Duffie, J.A and Beckman W.A. 2006. Solar Engineering of Thermal Processes. In Solar Engineering of Thermal Processes, Wiley, New York. 
Eicker, U. 2006. Solar technologies for buildings. John Wiley \& Sons, Chichester.

Gajbert, H., Hall, M., and Karlsson, B., 2007, “Optimisation of reflector and module geometries for stationary, low-concentrating, facade-integrated photovoltaic systems", Solar Energy Materials and Solar Cells, Vol 91, pp. 1788-1799

Fudholi, A., Sopian, K., Yazdi., M.H., Ruslan, M.H., Ibrahim, A. and Kazem H.A. 2014. "Performance analysis of photovoltaic thermal (PVT) water collectors", Energy Conversion and Management, Vol 78, pp 641-651.

Goswami, Y. D., 2000, “Principles of solar engineering”, Taylor and Francis, Philadelphia

Ibrahim, A., Fudholi, A., Sopian, K., Othman, M.Y., and Ruslan, M.H., 2014, "Efficiencies and improvement potential of building integrated photovoltaic thermal (BIPVT) system" Energy Conversion and Management, Vol 77, pp. 527-534

IEA, 2011, “Solar Energy Perspectives OECD Publication”, International Energy Agency, Paris

Kostic, L.T., Pavlovic, T.M., and Pavlovic, Z.T. 2010, “Optimal design of orientation of PV/T collector with reflectors", Applied Energy, Vol 87, pp. 3023-3029

McDaniels, D.K., Lowndes, D.H., Mathew, H., Reynolds, J., and Gray, R., 1975, "Enhanced solar energy collection using reflector-solar thermal collector combinations", Solar Energy, Vol 17, pp. 277283.

Notton, G., Cristofari, C., Mattei, M., and Poggi, P. 2005, "Modelling of a double-glass photovoltaic module using finite differences", Applied Thermal Engineering, Vol 25, pp. 2854-2877

Petter, B., Breivik, C., and Drolsum, R. 2012, "Building integrated photovoltaic products: A state-ofthe-art review and future research opportunities", Solar Energy Materials and Solar Cells, Vol 100, pp. 69-96

Piratheepan, M., 2016, Building integrated solar concentrators for façade applications, $\mathrm{PhD}$ thesis, Auckland University of Technology

Piratheepan, M., and Anderson, T. N., 2015, "Natural convection heat transfer in façade integrated solar concentrators", Solar Energy, Vol 122, pp. 271-276

Rabl, A. 1976, “Comparison of solar concentrators”, Solar Energy, Vol 18, pp. 93-111 
Tanaka, H., 2011, "Solar thermal collector augmented by flat plate booster reflector: Optimum inclination of collector and reflector". Applied Energy, Vol 88, pp. 1395-1404.

Tripanagnostopoulos, Y. 2012, "Photovoltaic/thermal solar collectors" Comprehensive Renewable Energy, Vol 3, pp 255-300.

Tripanagnostopoulos, Y., Nousia, T., Souliotis, M., and Yianoulis, P., 2002, "Hybrid photovoltaic/thermal solar systems", Solar Energy, Vol 72, pp. 217-234

Tselepis, S. and Tripanagnostopoulos Y. 2002, "Economic analysis of hybrid photovoltaic/thermal solar systems and comparison with standard PV modules", Proceedings of the International Conference on PV in Europe, Rome,2012.

Yang, L., Chen, L., and Catalano, A., 1991, "Intensity and temperature dependence of photo degradation of amorphous silicon solar cells under intense illumination", Applied Physics Letters, Vol 59 , pp. $840-842$

Zondag, H. A., 2008, "Flat plate PV-Thermal collectors and systems: A review", Renewable and Sustainable Energy Reviews, Vol 12, pp. 891-959

Zondag, H.A., de Vries, D.W., van Helden, W.G.J., van Zolingen, R.J.C., and van Steenhoven, A.A., 2002, "The thermal and electrical yield of a PV-thermal collector", Solar Energy, Vol 72, pp. 113-128 